\title{
Article \\ Empirical and Numerical Analysis of an Opaque Ventilated Facade with Windows Openings under Mediterranean Climate Conditions
}

\author{
Carlos-Antonio Domínguez-Torres ${ }^{1, *}$, Ángel Luis León-Rodríguez ${ }^{2} \mathbb{D}$, Rafael Suárez ${ }^{2} \mathbb{D}$ \\ and Antonio Domínguez-Delgado ${ }^{3}$ ii \\ 1 Escuela Técnica Superior de Arquitectura, Universidad de Sevilla, Avda. Reina Mercedes 2, \\ 41012 Sevilla, Spain \\ 2 Instituto Universitario de Arquitectura y Ciencias de la Construcción, Escuela Técnica Superior de \\ Arquitectura, Universidad de Sevilla, Avda. Reina Mercedes 2, 41012 Sevilla, Spain; leonr@us.es (Á.L.L.-R.); \\ rsuarez@us.es (R.S.) \\ 3 Department of Applied Mathematics 1, Escuela Técnica Superior de Arquitectura, Universidad de Sevilla, \\ Avda. Reina Mercedes 2, 41012 Sevilla, Spain; domdel@us.es \\ * Correspondence: cdtorres@us.es
}

check for updates

Citation: Domínguez-Torres, C.-A.; León-Rodríguez, Á.L.; Suárez , R.; Dominguez-Delgado, A. Empirical and Numerical Analysis of an Opaque Ventilated Facade with Windows Openings under Mediterranean Climate Conditions. Mathematics 2022, 10, 163. https:// doi.org/10.3390/math10010163

Academic Editors: Arturo Hidalgo and Frank Werner

Received: 29 September 2021 Accepted: 24 December 2021

Published: 5 January 2022

Publisher's Note: MDPI stays neutral with regard to jurisdictional claims in published maps and institutional affiliations.

Copyright: (C) 2022 by the authors. Licensee MDPI, Basel, Switzerland. This article is an open access article distributed under the terms and conditions of the Creative Commons Attribution (CC BY) license (https:// creativecommons.org/licenses/by/ $4.0 /)$.

\begin{abstract}
In recent years, there has been growing concern regarding energy efficiency in the building sector with energy requirements increasing worldwide and now responsible for about $40 \%$ of final energy consumption in Europe. Previous research has shown that ventilated façades help to reduce energy use when cooling buildings in hot and temperate climates. Of the different ventilated façade configurations reported in the literature, the configuration of ventilated façade with window rarely has been studied, and its 3D thermodynamic behavior is deserving of further analysis and modeling. This paper examines the thermal behavior of an opaque ventilated façade with a window, in experimentally and numerical terms and its impact in energy savings to get indoor comfort. Field measurements were conducted during the winter, spring and summer seasons of 2021 using outdoor full scale test cells located in Seville (southern Spain). The modeling of the ventilated façade was carried out using a three-dimensional approach taking into account the 3D behavior of the air flow in the air cavity due to the presence of the window. The validation and comparison process using experimental data showed that the proposed model provided good results from quantitative and qualitative point of view. The reduction of the heat flux was assessed by comparing the energy performance of a ventilated façade with that of an unventilated façade. Both experimental and numerical results showed that the ventilated façade provided a reduction in annual total energy consumption when compared to the unventilated façade, being compensated the winter energy penalization by the summer energy savings. This reduction is about $21 \%$ for the whole typical climatic year showing the ability of the opaque ventilated façade studied to reduce energy consumption to insure indoor comfort, making its suitable for use in retrofitting the energy-obsolete building stock built in Spain in the middle decades of the 20 century.
\end{abstract}

Keywords: optimization; cool roof; thermal insulation; aging effect; social housing; life cycle cost analysis

\section{Introduction}

In recent decades, there has been a notable increase in interest in the development of passive systems to achieve internal comfort in buildings due to the need to decrease energy costs. Given that buildings are responsible for almost half of the energy consumptions in Europe and that the energy requirements to ensure indoor comfort are increasingly being updated worldwide [1], regulations have been established for the reduction of energy consumption in buildings in compliance with the H2030 guidelines set by the EU [2]. 
In Spain, a large percentage of the current housing stock was built in the 1960s and 1970s to meet the high demand for housing in cities resulting from various socioeconomic factors. These homes tend to lack an adequate energy treatment of the envelope, which translates into situations of discomfort, energy poverty or excessive energy expenditure to achieve interior comfort.

Therefore, there is a pressing need to implement refurbishment measures that help to mitigate these problems. Among the possible construction systems that can be used in the retrofitting of façades in hot climates, the opaque ventilated façade (OVF) has demonstrated its ability to reduce inward heat flux and, consequently, to diminish energy consumption for conditioning, specially in the cooling season, [3-9]. Additionally, OVFs can be made of conventional materials, which reduce costs and, on the other hand, can be easily installed as work is not required on the inside of the building. This makes OVFs suitable for building retrofit in warm climates, even more so in the context of social housing built in the period mentioned earlier, which is usually inhabited by low-income homeowners reluctant to carry out costly retrofits. On the other hand, OVFs offer many posibilities for architectural design as well as a large variety of aesthetic possibilities. All of which makes OVFs suitable for use both from the point of view of the retrofitting of energy obsolete buildings and for new construction.

Opaque ventilated façades are made up of two layers separated by an air cavity which usually has an inlet opening through which the outside air enters the cavity and an outlet opening to return the air to the environment. However, other possible configurations can be found in the literature, for example, ventilated façades with open joints, also with a widespread use. The main difference of the OVF in relation to the double skin façade frequently used in cold climates is that in hot climates the outer slab or cladding is usually opaque to solar radiation, while in cold climates it is usually glazed. Thus, in an OVF the solar radiation is absorbed and reflected by the outer layer, reducing solar gain.

In the last two decades, research on ventilated facades has undergone a remarkable development, giving rise to a large number of works on different aspects of them. Given the vast extension of literature on OVFs, only a few works are mentioned to illustrate the research carried out on them.

The impact of the radiation on the velocity of the air into the ventilated channel was investigated in $[10,11]$ and Peci et al. [12] found that wind speed and direction and solar radiation are the driving forces of air flow and that if the wind speed is the prevalent driving force, temperatures are lower, and if buoyancy is the main driving force, temperatures rise. Many works have focused to analyze the influence of the values of solar radiation intensity in energy savings $[3,4,10,13]$ while the effect of the solar radiation and building orientation in the thermodynamic and energy performance of the OVFs has been studied in $[4,5,8,13,14]$.

The influence of the characteristics of the air ventilated channel on the air flow was investigated in $[3,4,6,13]$ and in $[4,5,15,16]$ was analyzed the effect of different materials for the layers that define the enclosure of the OVF. Stazi et al. [10] analyzed different external enclosures and found that the external cladding inertia influences the chimney effect over time, likewise, the outer layer was studied by Marinosci et al. [6] who assessed the effect of the openings, the air cavity thickness and the outer layer material on the performance of the OVFs. Thus, Stazi et al. [15] investigated the impact of different materials and thermal masses on the performance of ventilated façades with narrow cavities; this was done by measuring the variation in terms of heat flows and ventilation efficiency; authors concluded that the use of a massive material in the outer side of a narrow gap provided the optimal solution on annual basis, considering the thermophysical performance and the natural ventilation potential. Gregório-Atem et al. [16] studied the effect of OVFs in office buildings; in this analysis thirty constructive configurations were used for eight tropical climate conditions under eight tropical climate conditions; also, three different options for the outer layer and two for the inner layer were considered; results suggested the possibility of select the best configuration among the different configurations analyzed for each of the 
climate conditions in Brazil. De Masi et al. [17] discussed the environmental and thermal characterization of an innovative opaque open-joint ventilated façade whose components had a high degree of recycled materials; from the study carried out, it was found that the proposed solution was able of meeting energy efficiency and low impact throughout the life cycle point of view. In [18] three types of OVFs were studied experimentally, while in [19] was analyzed the effect of PCM use on the energy behavior of ventilated facades. The integration of photovoltaic systems into ventilated façades was analyzed experimentally and/or numerically in [20-23], while in $[8,10,24,25]$ was studied the effect of different configurations and materials of the exterior slab on the energy performance of OVFs. In [26], a field experimental study was carried out to evaluate the effect of a prefabricated ventilated facade.

In $[27,28]$, the hygrothermal performance of the OVF is linked to its energy saving potential.

Regarding the reduction of solar gains and energy savings, Fantucci et al. [29] assessed the effect of OVFs to reduce solar gains and found that this reduction was in a range between $52 \%$ and $64 \%$. Patania et al. [5] used the Fluent software to investigate the thermal behavior of three different types of ventilated façades; the authors concluded that for the summer period, the ventilated façades achieved energy saving rates of more than $40 \%$ over unventilated ones. Marinosci et al. [30] used ESP-r software for the experimental and numerical study of the energy performance of a ventilated façade with a rain screen; based on the thermal analysis carried out, the authors concluded that the façade studied is capable of reducing energy consumption for indoor heating and that the numerical model built with ESP-r is useful for engineering design. Giancola et al. [8] experimentally and numerically analyzed the energy behavior of an open joint ventilated façade; from the experimental monitoring they concluded that in hot climates with high solar radiation, ventilated façades can reduce heating and cooling thermal loads when outdoor temperatures are not extreme; in addition, they developed a simulation model using Fluent software that exhibited good numerical properties, predicting temperatures and heat fluxes with errors below $10 \%$. Gagliano et al. [9] performed CFD simulations during the summer for different wind conditions and calculated the heat flux through a ventilated and an unventilated façade; the authors concluded that that there was a $47-51 \%$ reduction in heat flux through the ventilated facade compared to the unventilated one.

The effect on the energy saving of OVFs of design has been analyzed in [14,31] while in $[9,14,16,29,32-34]$ the effect of climate conditions on energy saving potential was analyzed. Peci and Ruiz [32] carried out a sensitivity analysis considering the most important weather variables in 12 locations in Spain; the energy saving values in the winter were evaluated using a numerical model previously validated with experimental data; results showed that the most influential variable was solar radiation and that a combination of high temperatures and low wind speeds can also produce significant energy savings, in addition, it was found that the most convenient locations for installing an OVF were those with low and medium winter severity climates. Fernandes Maciel and Tereza Carvalho [35] investigated the energy benefit of OVFs compared to cladding façades in multi-floor residential buildings in nine Brasil climate zones; the analysis was performed through numerical simulation for a whole year; in addition, they performed a cost-benefit analysis taking into account the cost of implementing the OVF in each location and the yearly energy benefits; they found that the greatest energy benefits and the best cost-benefits were obtained in the hottest zones; the method used by authors to perform this investigation was presented in [36]. Fantucci et al. [37] conducted an extensive in-field experiment in summer on different large-scale OVF configurations with the objective of assessing the thermal performance of a OVF based on hollow clay claddings technology; all the OVF configurations analyzed were compared with an unventilated reference façade, obtaining results consistent with those reported in the literature; from the sensitivity analysis performed, authors concluded that all the investigated façade features, external colour, channel height, ventilation grills have a meaningful impact on the energy performance of the OVF. 
The effect of the insulation characteristics on the energy savings of OVFs have been studied in [4] where was found that the positioning of the insulating layer close to the inner masonry wall was more efficient than the one close to the outer later. Nizovtsev et al. [38] conducted a full-scale and laboratory experiments to analyze the effect of a paneled OVF on the moisture condition of thermal insulation; the authors concluded that even under high levels of ambient humidity, the insulation material maintained low levels of humidity providing high protection of the thermal properties of the panels.

More references on OVFs can be found in [39] where a review addressed to the thermal and the energy performance of OVFs is carried out.

A review of the existing literature on ventilated façades shows that ventilated façades with window openings have barely been studied. Usually, the study of ventilated façades does not consider the presence of window openings on the façade, so the impact of these openings on the air flow inside the ventilated channel and therefore on the thermodynamic behavior of the FV is not taken into account. This lack of study is both for experimental measurements and for the development of simulation models. It can therefore be stated that there is a gap in the literature regarding the performance analysis of the OVF configuration with window openings addressed in this study.

In this paper, the thermal behavior of an opaque ventilated façade with window openings and its effect on the flow of energy into the building, has been investigated both experimentally and numerically. The goal of this work is to calculate the energy performance of an OVF with window openings and to assess its impact on the thermal loads to get indoor comfort and to identify its energy saving potential compared to an identical façade without the elements making up the OVF: an outer slab and an insulation layer. The final objective of this comparison is to establish its usefulness as a constructive solution proposal for the energy retrofitting of the building envelopes of the housing stock built in the South of Spain in the middle decades of the 20 century.

For this, a double experimental and numerical analysis was performed. For the experimental study, two full-scale outdoor test cells located in the city of Seville, southern Spain, were used. This city is characterized by high levels of solar radiation, hot summers and warm winters. According to previous literature [5,8], the use of ventilated façades to retrofit poorly insulated buildings is expected to yield energy savings and to reduce energy consumption to ensured indoor comfort in the hot season.

One of the test cells reproduces an unventilated façade (UVF) commonly used in southern Spain in the in the 1960s and 1970s, prior to the implementation of the first Spanish legislation for the regulation of energy demand in buildings, the NBE-CT-79 [40]. The second test cell has the same constructive configuration as the previous one, but has been retrofitted by adding an OVF system. Both test cells have a window on the south façade. The inlet of the OVF was placed at the bottom of the façade and was equipped with a system of slats to control the flow of air entering the ventilated cavity when opening or closing.

Both test cells are equipped with sensors to measure the variables needed to appraise the energy performance of the facades and its impact on indoor temperatures. Data were recorded and analyzed for various protocols of use of the OVF and the cells throughout the first half of 2021.

For the numerical study, a simulation model was developed that uses a coupling between the CFD modeling of the air flow inside the OVF and a calculation of the heat transfer through the cell envelope, allowing to evaluate the impact of the use of the OVF on the overall thermal behavior of the test cells. The numerical model was validated using the monitoring data and the simulation results were compared with the experimental data in order to evaluate the ability of the model to predict the qualitative behavior of the OVFenergy performance.

Finally, once the method was validated, it was used to estimate the yearly energy savings of the OVF when compared with the UVF, under the climate framework consid- 
ered. Based on these computations, conclusions were drawn regarding the energy saving potential of the OVF when used in the retrofitting of energy-obsolete buildings.

The paper is organized as follows: in Section 2, the methodology followed in the present work is described; in Section 3 the experimental set-up used in the monitoring process is described; in Section 4, the physical assumptions and mathematical modeling of both the OVF and the whole test cell are described; in Section 5, details about the numerical simulation are reported; Section 6 shows results from monitoring and simulation for the different protocols and time periods considered, along with the comparison of measured and simulated outputs for the validation of the model presented; in Section 7, the model is applied to the assessment of the energy savings provided by the OVF; in Section 8 a comparison between the 3D model presented and a 2D model for the OFV analyzed is carried out; finally, in Section 9 the conclusions and future work are presented. Two Appendices are added to provide information on the equations for the air flow and some additional details on the numerical discretization used in the simulations.

\section{Methodology}

Figure 1 shows a diagram of the methodology followed.

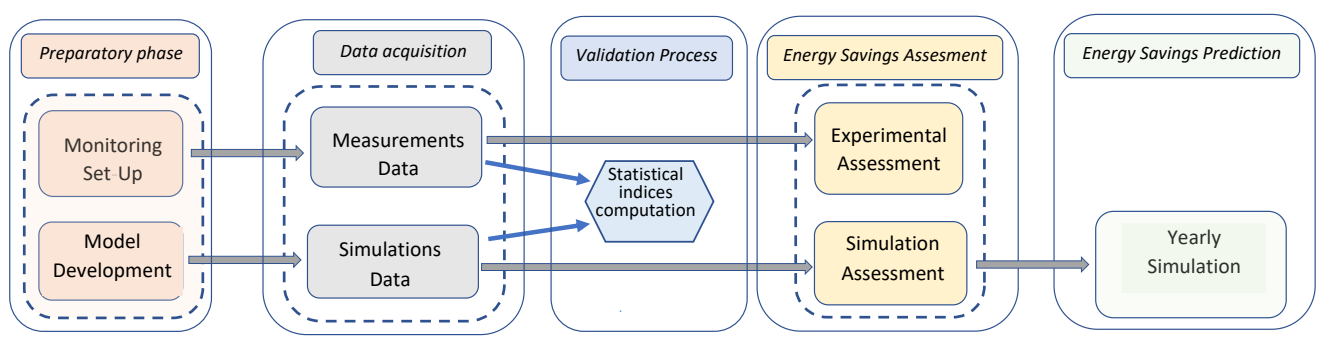

Figure 1. Flow chart of the used methodology.

In the first stage, the monitoring set-up and the numerical model for the simulation of the energy behavior of the OVF were prepared. For the monitoring set-up, two outdoor full-scale test cells were equipped with a large number of sensors to record temperatures and velocities, as detailed in Section 3. In the same preparatory stage, the simulation model to compute the energy performance of the OVF and the whole test cells were developed as described in Section 4.

In the second stage, data acquisition was carried out using monitoring during different time periods in winter, spring and summer as described in Section 6.1. For the data acquisition from simulation, the model presented was used to simulate the thermodynamical behavior of the OVF during the same time periods used for monitoring in order to compile data for the validation of the numerical model. This process is described in Section 6.2.

In the third step, a validation process was carried out to establish the validity of the simulation model presented. This process focused primarily on the most commonly statistical indices for the validation of energy building software and the comparison of measured and simulated outputs. This step is described in Sections 6.2.2 and 6.2.3.

In the following stage, an analysis of the energy savings due to the use of the OVF when compared to the UVF, was carried out based on the monitored data. In addition, the assessment of the energy savings for the same time intervals was carried out by using the simulation outputs; finally in this stage, estimations of the error for the computed energy savings were obtained. This is developed in Section 7.

In the next stage, the validated simulation model was used to ascertain the energy savings provided by the OVF when compared to the UVF, for a typical climatic year in the city of Seville. This step, detailed in Section 7.2 provided conclusions about the winter penalty and the summer energy savings.

At the last stage, a comparison is shown between the results obtained for the presented 3D model and a 2D model used to predict the energy performance of the OVF with window 
opening. This comparison of results and errors allows evaluating the limitations of 2D modeling for the analyzed OVF.

\section{Experimental Setup}

\subsection{Test Cells Description}

The test cells used in the experimental measurements are located in Spain, Seville (latitude $37^{\circ} 22^{\prime}$, longitude $-5^{\circ} 58^{\prime}$, altitude $14 \mathrm{~m}$ ). They were built in an outdoor area belonging to the University of Seville, in the center of the city. The installation is surrounded by a land area stretching $21 \mathrm{~m}$ and $35 \mathrm{~m}$ to the south and east sides, respectively, and $6 \mathrm{~m}$ on the west and north sides.

The facility consists of two independent modules $90 \mathrm{~cm}$ off the ground and symmetrically located on both sides of an access zone on a longitudinal axis N-S. Each module is made up of two test cells facing north and south and connected by a non-climatized service room for equipment, Figure $2 \mathrm{a}, \mathrm{b}$. The interior dimensions of the four test cells are $2.40 \mathrm{~m}$ wide, $3.20 \mathrm{~m}$ deep, and $2.70 \mathrm{~m}$ high.

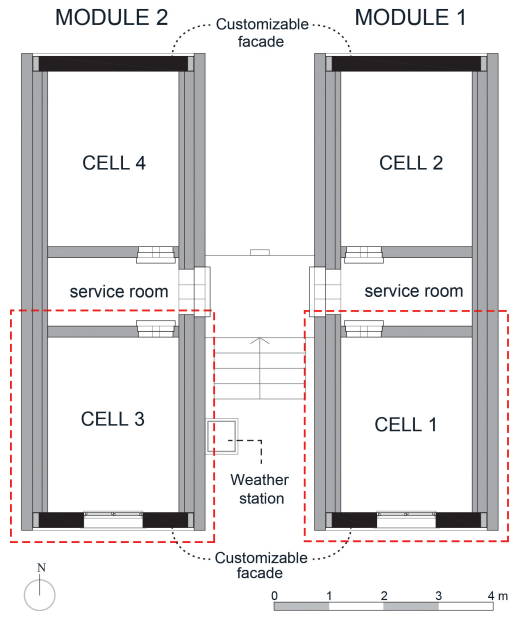

(a)

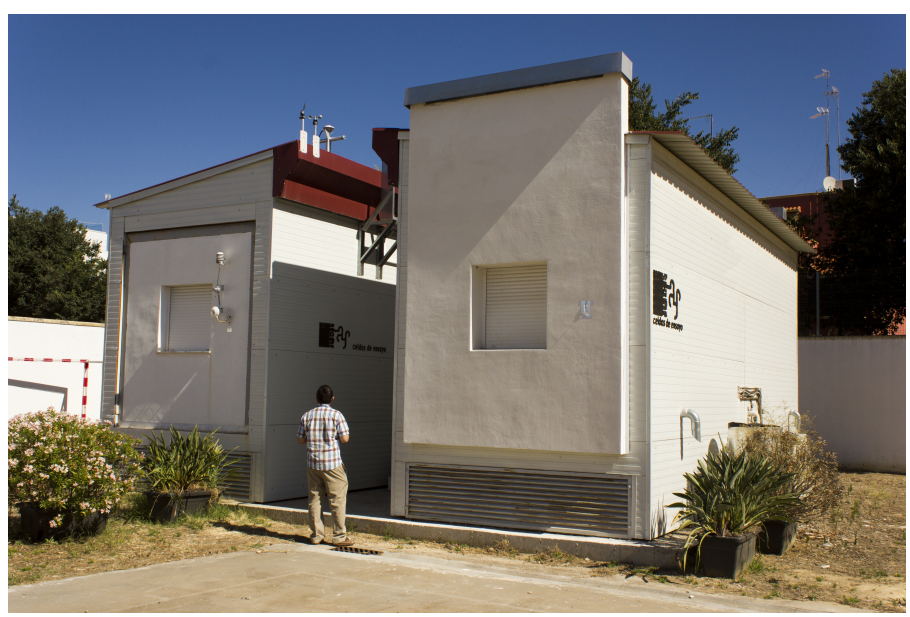

(b)

Figure 2. (a) Floor plan of the test cells; (b) external view of Cell 1 with the OVF (right) and Cell 3 with the UVF (left).

The southern façade of Cell 3 reproduces a constructive solution commonly used in social housing in Southern Spain, before the implementation of the first Spanish legislation for the regulation of energy demand in buildings, the NBE-CT-79 [40]. A $116 \times 108 \mathrm{~cm}$ window with 4.8.4 double glazing and an aluminum frame and slatted PVC shutters was installed on the southern façade of Cell 3.

The east and west walls, the roof and the floor slabs of the cells are made up of white highly insulated panels with a global thermal transmittance value of $0.05 \mathrm{~W} / \mathrm{m}^{2} \mathrm{~K}$. Moreover, the cell roof is covered by a sloping layer of galvanized corrugated sheet panels forming a ventilated chamber while the floor is separated from the soil by a non-climatized space. The north wall in contact with the non-climatized service room is made of a sandwich panel $100 \mathrm{~mm}$ thick with the same thermophysical values as the sandwich panels used for the east and west walls.

The retrofitted façade in Cell 1 results from the addition of an opaque ventilated façade system to a façade similar to the southern façade of Cell 3, while keeping the existing window in place keeping the existent window in place. Therefore the Cell 1 southern façade has the same construction layers as the southern façade in Cell 3, plus a layer of wool rock of $0.05 \mathrm{~m}$ thick attached to the external wall surface, an air gap of $0.1 \mathrm{~m}$ thick and an outer layer of $0.0135 \mathrm{~m}$ thick made of a plate composed of a Portland cement core and a fiberglass mesh embedded on both sides being its outer surface finished by a layer of rendering mortar and having its inner surface attached a waterproof coat. 
The air cavity was closed laterally with the same material as the outer layer, and it is connected to the exterior through an inlet opening of the same width as the air gap at the bottom of this last. This opening is equipped with a system of grids that allows it to be opened and closed in such a way that the resulting opening area, when the grids are opened, is the $50 \%$ of the total area of the ventilated chamber base. An additional opening is located at the top and equipped with an overhang measuring approximately $20 \mathrm{~cm}$ to protect the exterior from rain.

The layering of the envelopes is described in Tables 1-3. The values shown are the nominal values for the materials provided by the Spanish Technical Building Code [41] and the manufacturers.

Table 1. Thermophysical properties of the Cell 3 southern wall.

\begin{tabular}{llllll}
\hline Layer & Description & $\begin{array}{l}\text { Thickness } \\
\mathbf{( m )}\end{array}$ & $\begin{array}{l}\text { Density } \\
\mathbf{( k g / \mathbf { m } ^ { 3 } )}\end{array}$ & $\begin{array}{l}\text { Specific Heat } \\
\mathbf{( J / k g ~ K )}\end{array}$ & $\begin{array}{l}\text { Conductivity } \\
\mathbf{( W / m ~ K )}\end{array}$ \\
\hline 1 (Out.) & Cement rendering & 0.015 & 1300 & 1000 & 0.67 \\
2 & Perforated brick & 0.115 & 780 & 1000 & 0.35 \\
3 & Cement rendering & 0.010 & 1300 & 1000 & 0.67 \\
4 & Air chamber & 0.05 & 1.184 & 1007 & 0.02551 \\
5 & Hollow brick & 0.04 & 770 & 1000 & 0.32 \\
6 (In.) & Gypsum plaster & 0.015 & 1000 & 1000 & 0.57 \\
\hline
\end{tabular}

Table 2. Thermophysical characteristics of east and west walls and roof.

\begin{tabular}{llllll}
\hline Layer & Description & $\begin{array}{l}\text { Thickness } \\
(\mathbf{m})\end{array}$ & $\begin{array}{l}\text { Density } \\
\mathbf{( k g / \mathbf { m } ^ { 3 }}\end{array}$ & $\begin{array}{l}\text { Specific Heat } \\
\mathbf{( J / k g ~ K )}\end{array}$ & $\begin{array}{l}\text { Conductivity } \\
\mathbf{( W / m ~ K )}\end{array}$ \\
\hline 1 (Out.) & Sandwich panel & 0.200 & 40 & 1884.15 & 0.017 \\
2 & Wool rock panel & 0.160 & 100 & 840 & 0.046 \\
3 (In.) & Sandwich panel & 0.100 & 40 & 1884.15 & 0.017 \\
\hline
\end{tabular}

Table 3. Thermophysical properties of the materials used in the OFV.

\begin{tabular}{llllll}
\hline Layer & Description & $\begin{array}{l}\text { Thickness } \\
(\mathbf{m})\end{array}$ & $\begin{array}{l}\text { Density } \\
\left(\mathbf{k g} / \mathbf{m}^{\mathbf{3}}\right)\end{array}$ & $\begin{array}{l}\text { Specific Heat } \\
\mathbf{( J / k g ~ K )}\end{array}$ & $\begin{array}{l}\text { Conductivity } \\
(\mathbf{W} / \mathbf{m ~ K})\end{array}$ \\
\hline 1 (Out.) & Cement rendering & 0.005 & 1300 & 1000 & 0.67 \\
2 & Reinforced cement board & 0.0125 & 1150 & 1000 & 0.35 \\
3 & Waterproof coat & 0.005 & 260 & 1000 & 0.026 \\
4 & Air gap & 0.1 & 1.205 & 1.006 & 0.046 \\
5 & Wool rock panel & 0.05 & 100 & 840 \\
$6-11$ (In.) & Same as layers 1 to 6 of the cell C3 southern wall (Table 1). & & \\
\hline
\end{tabular}

\subsection{Measurement Setup}

The test cells are fully equipped with instruments for measuring temperatures of the internal surfaces and the air of the internal cells. Each cell is equipped with four internal air temperature sensors and eight thermocouples to measure surfaces temperatures. The internal air temperature sensors are shielded against solar radiation and installed at different positions and heights $(1.5$ and $2.5 \mathrm{~m})$. The indoor air temperature is calculated as the mean of the temperatures provided by the four air temperature sensors.

Regarding the OVF, velocity and temperature sensors were placed on the centreline of the air cavity. This way, air temperatures and velocities inside the OFV were measured in a central position between the internal surface of the outer slab and the external surface of the internal wall at different heights and in five different positions. Temperatures of the exterior and interior surfaces of the outer slab and the exterior surface of the insulating layer were measured at the same heights as air. A sketch of the location of the sensors at 
the OFV is shown in Figure 3, whilst the location of the sensors in the test cells is shown in Figure 4.
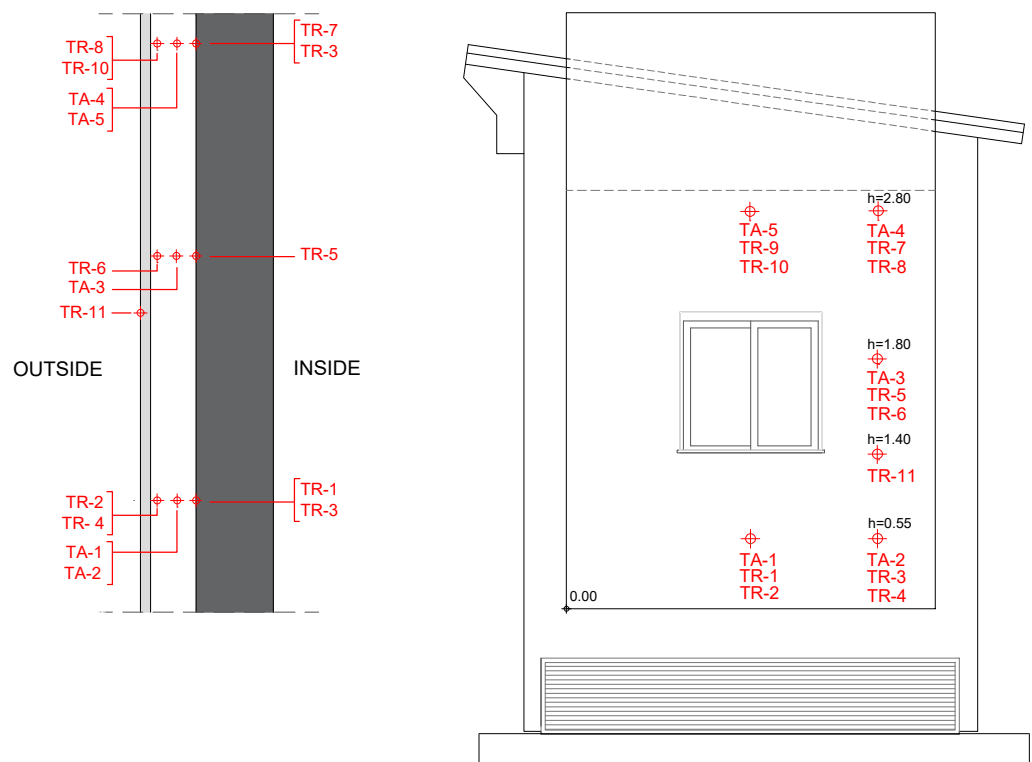

Figure 3. Position of the monitoring sensors in the OVF. TR: surface temperature sensors, TA: air velocity and temperature sensors (h indicates the height in meters).

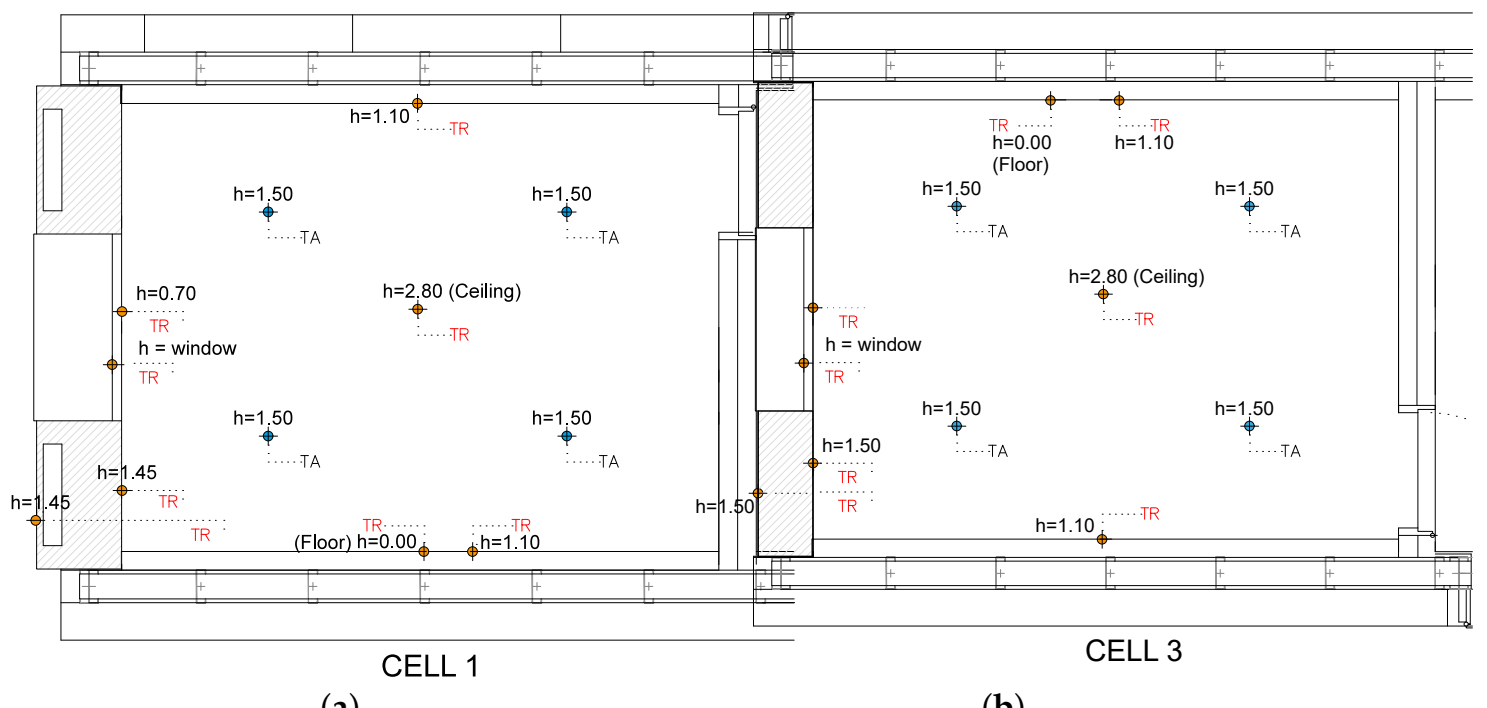

(a)

(b)

Figure 4. Location of the sensors in: (a) test cell 1; (b) test cell 3. (TA air temperature sensors, TR surface temperature sensors; $h$ indicates the height in meters).

The surface temperature sensors used are thermocouples of type $\mathrm{K}$ with an accuracy of $\pm 1{ }^{\circ} \mathrm{C}$ and an operating range from -10 to $105^{\circ} \mathrm{C}$. The air temperature sensors have an accuracy of $\pm 0.5^{\circ} \mathrm{C}$ for a range from +10 to $30^{\circ} \mathrm{C}$ and an accuracy of $\pm 1{ }^{\circ} \mathrm{C}$ for a range from -5 to $10^{\circ} \mathrm{C}$ and from 30 to $55^{\circ} \mathrm{C}$. All the temperature sensors were shielded against long and short-wave radiation.

The velocity sensors have an accuracy of $\pm 0.05 \mathrm{~m} / \mathrm{s}$ for a velocity range of 0.15 to $2 \mathrm{~m} / \mathrm{s}$, that is the usual velocity range found inside the air gap.

Weather variables were measured from a weather station located on the roof of the Cell 3. A set of five pyranometers was located on the test cell with orientations. Wind speed and direction were measured using an anemometer and a vane. The ambient temperature 
was measured using two shielded thermocouples. Table 4 shows the characteristics of the weather sensors. Measurements were recorded at $5 \mathrm{~min}$ intervals.

Table 4. Description of the sensors installed at the weather station on the Cell 3 roof.

\begin{tabular}{cccc}
\hline Measured Variable & Type of Sensor & Accuracy & Rank \\
\hline External air & Thermometer & $\pm 0.75{ }^{\circ} \mathrm{C}$ & $-40,80^{\circ} \mathrm{C}$ \\
temperature & Anemometer & $\pm 0.5 \%$ & 0 to $50 \mathrm{~m} / \mathrm{s}$ \\
Wind speed & Vane & $\pm 2.5 \%$ & 0 to $360^{\circ}$ \\
Wind direction & Hygrometer & $\pm 3 \%$ & 0 to $100 \%$ \\
Relative humidity & Pyranometer & $\pm 1.5 \%$ & 0 to $2000 \mathrm{~W} / \mathrm{m}^{2}$ \\
Global irradiance & Pyranometer & $\pm 1.5 \%$ & 0 to $2000 \mathrm{~W} / \mathrm{m}^{2}$ \\
Diffuse irradiance & &
\end{tabular}

The measurements have been carried out for distinct experimental protocols, with open and closed opening grills, to investigate the influence of the different ventilation grills configurations on the OVF energy performance under different climate conditions: winter, spring and summer. In the experimental monitoring, the window blind was left closed and HVAC and ventilation systems were kept off.

\section{Modeling Setup}

The heat transfer through the OVF is determined by:

- Heat gain on the external surface of the outer slab due to solar irradiation.

- Heat exchange by radiation between the environment and the external surface of the outer slab.

- $\quad$ Heat exchange by radiation between the sky and the external surface of the outer slab.

- Heat exchange by convection between the ambient air and the external surface of the outer slab.

- $\quad$ Heat transfer by conduction through the outer slab.

- $\quad$ Radiative heat exchange between the surfaces which delimit the ventilated chamber.

- $\quad$ Convective heat exchange between the surfaces of the ventilated chamber and the air flowing inside it.

- $\quad$ Heat transfer by conduction through the inner wall.

- Heat exchange by convection between the internal surface of the inner wall and the cell indoor air.

- Heat exchange by radiation between the internal surface of the inner wall and the internal surfaces of the cell envelope.

A sketch of these fluxes is shown in Figure 5.

The energy performance of the OVF can be summarized as follows: in daylight hours the outer layer is reached by solar radiation; on the other hand, throughout the whole day the external layer exchanges thermal long-wave radiation with the ground, the environment and the sky; at the same time, this layer exchanges heat by convection with outdoor air. All these contributions result in a heat flux by conduction through the outer wall.

Within the air chamber, thermal radiative exchange between the channel surfaces takes place, as well as heat transfer by convection between these surfaces and the air in the chamber.

On the other hand, natural convection and the air that enters the ventilated cavity through the OVF opening conditions the speed of the air that flows through the ventilated chamber.

Furthermore, the convective heat transfer between the external surface of the outer layer and the ambiance air is conditioned by its velocity and temperature that are influenced by velocity and temperature of the air incoming the domain and the temperature of the ground external surface. 
The heat transfer process is completed with heat conduction through the inner wall and with the heat transfer by convection between the interior surface of the wall and the indoor air room, and by thermal radiation with the other walls inside the room.

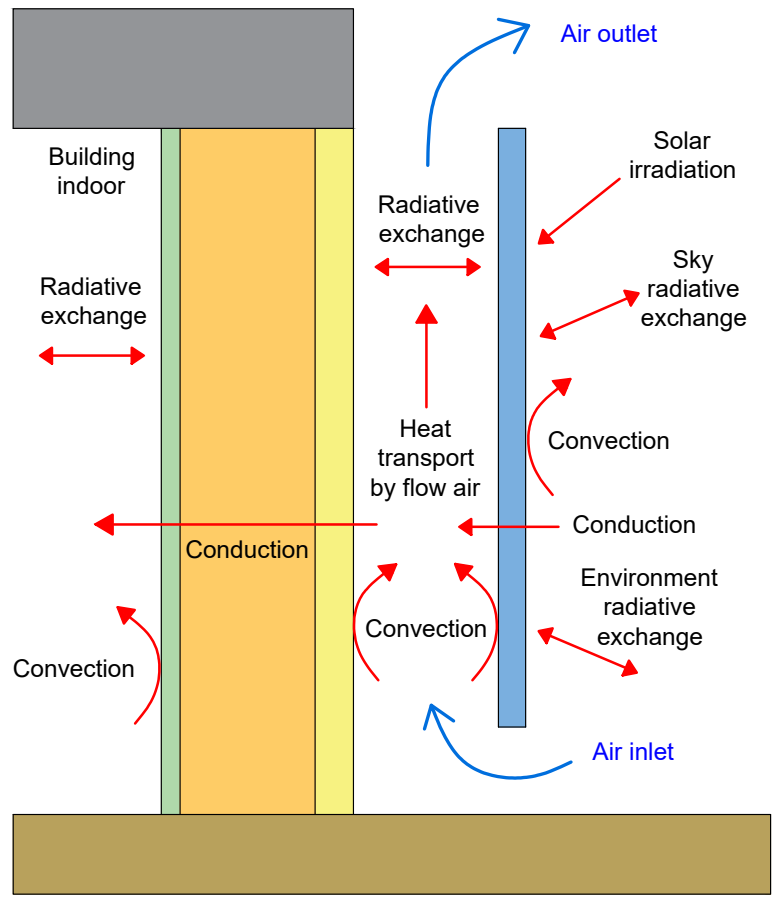

Figure 5. Heat transfer in the opaque ventilated façade.

To establish the physical model, it should be considered that air flowing in the air cavity removes or adds heat to the cavity surfaces at a rate determined mainly by the velocity of the air flowing throughout the air channel and by the difference in temperatures between the channel walls and the air.

All that implies that at each time step, thermodynamic equations for the air flow, heat conduction equations through solid layers of the OVF and the ground must be solved at same time that radiative exchanges among the surfaces are computed to approximate accurately the thermal transfer through the ventilated façade.

Finally, it should be noted that the presence of the window introduces an obstacle to the flow of air through the ventilated chamber, which which makes the air flow clearly three-dimensional. Thus, the two-dimensional hypothesis usually applied in the modeling of ventilated façades is not suitable in this case, so that three-dimensional modeling of the thermodynamic behavior of the airflow in the OVF is needed.

\subsection{OVF Modeling}

The OVF in Cell 1 was modeled as a three-dimensional system. The governing equations for the air flow and transport temperature are the thermodynamic Navier-Stokes equations with a Boussinesq approximation for buoyancy. Additionally, a modeling of the turbulence through the RNG $\kappa-\varepsilon$ model was used to simulate the turbulence following [42] where is stated that the RNG $\kappa-\varepsilon$ turbulence model performed better than other turbulence models to compute heat transfer when the air has zones of low velocity in the ventilated chamber. The equations used in the model are shown in Appendix A.

Regarding the air flow, the condition of non-slip velocity is imposed on all the solid surfaces; in the air inlet to the computational domain, the wind velocity was computed using the expression:

$$
U(h)=U_{r}\left(\frac{h}{h_{r}}\right)^{\gamma} \quad[\mathrm{m} / \mathrm{s}]
$$


where $U(h)$ is the value of the wind velocity at height $h, U_{r}$ is the wind speed at the reference altitude $h_{r}$ and $\gamma$ a coefficient whose value depends on orography and roughness of surroundings. This expression has been used in the analysis of the impact of wind velocity in the analysis of the energy performance of OVFs [9]. In order to compute the air velocity at the inlet of the ventilated chamber, a portion of the outdoor environment around the cells is included in the computational domain as is shown in Figure 6. At the top of the computational domain, slip condition is imposed and finally free outflow in the remaining boundary surfaces.

The boundary values for temperature are given by the energy balance equations described in Sections 4.1.1 and 4.1.2.

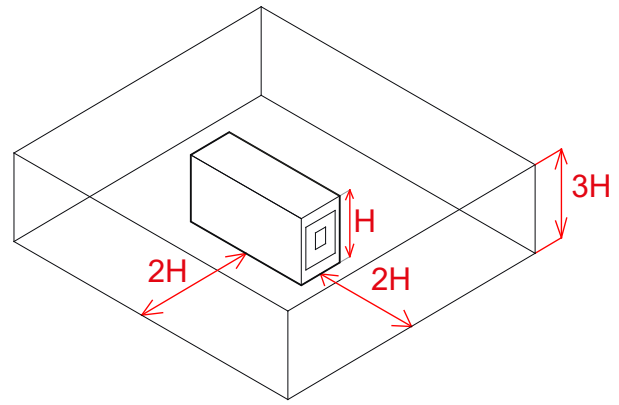

(a)

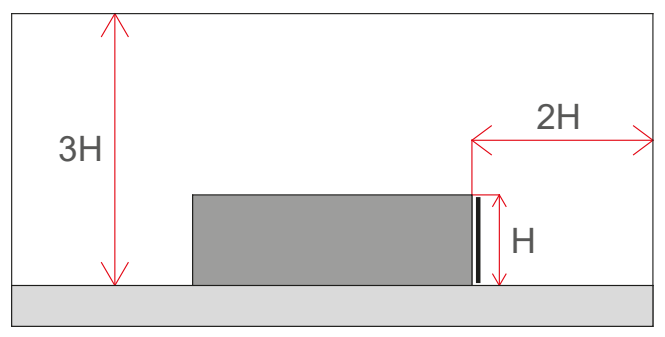

(b)

Figure 6. Non-scaled sketch of the computational domain: (a) 3D view; (b) longitudinal section.

\subsubsection{Energy Balance at the Exterior Surface of the OVF}

The energy balance at the exterior surface of the outer slab is

$$
\kappa \frac{\partial T_{S_{e x t}}}{\partial \vec{n}}+q_{e x t}+q^{S W}+q^{L W}=0
$$

where $\vec{n}$ is the outward normal vector to the external surface $S_{\text {ext }}$ of the outer slab; $\kappa$ is the conductivity of the material making up this surface and $T_{S_{e x t}}$ is the temperature at surface $S_{\text {ext }} ; q_{\text {ext }}$ is the intensity of the convective heat flux between the surface and the air flow given by:

$$
q_{\text {ext }}=h_{\text {ext }}\left(T_{a m b}-T_{S_{e x t}}\right), \quad\left[\mathrm{W} / \mathrm{m}^{2}\right],
$$

being $T_{a m b}$ the outdoor air dry-bulb temperature and $h_{\text {ext }}$ the convective heat transfer coefficient described in Section 4.3. Finally, $q^{S W}$ is the intensity of radiative flux of solar origin on the surface and $q^{L W}$ is the intensity of the balance of thermal long-wave radiation at the surface $S_{\text {ext }}$ calculated as:

$$
q^{L W}=\epsilon_{S_{\text {ext }}} \sigma\left(F_{S_{\text {ext }}, g n d}\left(T_{\text {gnd }}^{4}-T_{S_{\text {ext }}}^{4}\right)+F_{S_{\text {ext }}, s k y}\left(T_{\text {sky }}^{4}-T_{S_{\text {ext }}}^{4}\right)+F_{S_{\text {ext }}, \text { surr }}\left(T_{\text {surr }}^{4}-T_{S_{\text {ext }}}^{4}\right)\right)
$$

where $\epsilon_{S_{\text {ext }}}$ is the long-wave emisivity of the surface $S_{\text {ext }} ; F_{S_{\text {ext }}, g n d}, F_{S_{\text {ext }}, \text { sky }}$ and $F_{S_{\text {ext }}, \text { surr }}$ are, respectively, the view factor of $S_{\text {ext }}$ to the ground surface, sky dome and surrounding. Here, $T_{\text {gnd }}$ is the temperature of the ground surface, $T_{\text {surr }}$ is the surrounding surfaces temperature and finally $T_{\text {sky }}$ is the sky temperature, all them expressed in Kelvin degrees. Following [43], $T_{\text {sky }}$ was calculated by the equation:

$$
T_{\text {sky }}=0.0375536 T_{a m b}^{1.5}+0.32 T_{a m b} \quad\left[{ }^{\circ} \mathrm{K}\right] .
$$

This approach to $T_{s k y}$ has been used former in previous research on OVF [9]. On the other hand, we have considered surrounding objects with a emissivity of 0.85 , typical for non-metallic surfaces [44]; $T_{\text {surr }}$ and $T_{\text {gnd }}$ are taken equal to the ambiance air temperature [45] 


\subsubsection{Duct Surfaces Energy Balance Calculation}

The energy balance for every surface $S_{\text {int }}$ facing the air cavity, is given by:

$$
\kappa \frac{\partial T_{S_{\text {int }}}}{\partial \vec{n}}+q_{\text {int }}+q^{L W}=0
$$

where $\vec{n}$ is the normal vector to the surface $S_{i n t}$, oriented towards air cavity; and $T_{S_{i n t}}$ is the temperature at surface $S_{i n t} ; \kappa$ is the conductivity of the material making up the surface $S_{\text {int }}$; $q_{\text {int }}$ is the intensity of the convective heat flux between the surface $S_{i n t}$ and the air inside the cavity given by:

$$
q_{\text {int }}=h_{\text {int }}\left(T-T_{S_{\text {int }}}\right), \quad\left[\mathrm{W} / \mathrm{m}^{2}\right],
$$

being $T$ the air temperature and $h_{\text {int }}$ the convective heat transfer coefficient describe in Section 4.3.

Finally, $q^{L W}$ is the long-wave radiative flux balance at the surface $S_{i n t}$. To compute $q^{L W}$ the radiosity method has been used. For it, the triangular surfaces facing the duct from the thretaedral 3d-discretization of the outer slab, the insulation layer and the lateral closures of the duct, are numbered from 1 to $N$. Then, the view factor $F_{i, j}$ between each pair of triangles $\mathcal{T}_{i}$ and $\mathcal{T}_{j}$, with $1 \leq i, j \leq N$ are calculated. Because the triangles are perpendicular or parallel to each other, $F_{i, j}$ can be calculated analytically [46].

The long-wave radiation heat flux emitted by each triangle $\mathcal{T}_{i}$ for $i=1, \ldots, N$, is given by:

$$
E_{i}^{L W}=\epsilon_{i} \sigma T_{i}^{4}
$$

where $\epsilon_{i}$ and $T_{i}$ are the emissivity and temperature (in Kelvin degrees) of $\mathcal{T}_{i}$.

This way, the long-wave radiative balance on $\mathcal{T}_{i}$, for $i=1, \ldots, N$ is given by:

$$
Q_{i}^{L W}=\sum_{j=1}^{N} J_{j}^{L W} F_{i, j}-J_{i}^{L W} \quad\left[\mathrm{~W} / \mathrm{m}^{2}\right],
$$

where $J_{i}^{L W}$ is the long-wave radiosity of $\mathcal{T}_{i}[46]$.

The values of $J_{i}^{L W}$ are computed by solving the system

$$
\mathbf{A}^{\mathrm{LW}} \mathbf{J}^{\mathrm{LW}}=\mathbf{E}^{\mathrm{LW}},
$$

with

$$
\begin{gathered}
\mathbf{A}^{\mathbf{L W}}=\left(\begin{array}{cccc}
1-\rho_{1} F_{1,1} & -\rho_{1} F_{1,2} & \cdots & -\rho_{1} F_{1, N} \\
-\rho_{2} F_{2,1} & 1-\rho_{2} F_{2,2} & \cdots & -\rho_{2} F_{2, N} \\
\vdots & \vdots & \cdots & \vdots \\
-\rho_{N} F_{N, 1} & -\rho_{N} F_{N, 2} & \cdots & 1-\rho_{N} F_{N, N}
\end{array}\right) \\
\mathbf{J}^{\mathbf{L W}}=\left(\begin{array}{c}
J_{1}^{L W} \\
J_{2}^{L W} \\
\cdots \\
J_{N}^{L W}
\end{array}\right), \quad \mathbf{E}^{\mathbf{L W}}=\left(\begin{array}{c}
E_{1}^{L W} \\
E_{2}^{L W} \\
\cdots \\
E_{N}^{L W}
\end{array}\right)
\end{gathered}
$$

where $\rho_{i}$ is the long-wave reflectance of $\mathcal{T}_{i}$ and $E_{i}^{L W}$ is computed by using Equation (6).

\subsubsection{Thermal Conduction through the Wall and Slabs of the OVF}

Heat conduction through the inner wall is modeled by the equation:

$$
\frac{\partial T}{\partial t}-\nabla \cdot(\alpha \nabla T)=0
$$


where the diffusivity coefficient $\alpha$ takes a value corresponding to each material of the various layers of the wall. The same equation is used for thermal conduction through the outer slab where now $\alpha$ is the thermal diffusivity of the slab material.

For the external surfaces of the outer slabs the boundary condition for Equation (9) is given by the energy balance equation corresponding to each slab external surface as it is explained in Section 4.1.1. For the slabs and the insulating surface facing the duct, boundary conditions are given by the energy balance equation corresponding to each surface as it is explained in Section 4.1.2.

For the inner layer of the mass wall the boundary condition is detailed in next section.

\subsection{Thermal Cell Modeling}

In this section, the modeling of the thermal behavior of the whole test cell is developed.

For it, the temperature of the indoor air and the internal surfaces of the cell have been taken as a single value [45] and for the sake of brevity, only the case of window blind closed is considered. Then, the one-dimensional version of Equation (9) is used for all the elements of the cell envelope, except for the southern wall that was incorporated to the computation of the OVF in a three-dimensional way. The boundary conditions for the external surfaces of the envelope are obtained from the energy balance equation corresponding to each surface, as is explained in Section 4.1.1.

For the cell indoor, seven internal surfaces are considered: the four wall internal surfaces, the floor, the ceiling and the inner surface of the window. The energy balance equation corresponding to each surface $j$ for $j=1, \ldots, 7$ is

$$
\kappa \frac{\partial T_{j}}{\partial \vec{n}}+q_{j, i n t}+q_{j}^{L W}=0,
$$

being now $q_{j, \text { int }}=h_{j, \text { int }}\left(T_{z}-T_{j}\right)\left[\mathrm{W} / \mathrm{m}^{2}\right]$, where $T_{z}$ is the indoor air temperature considered as a single value, $T_{j}$ the temperature of the interior surface $j$ belonging to the envelope and $h_{j, i n t}$ the interior convective heat transfer coefficient as is described in Section 4.3. In the computation of $q_{j, i n t}$, when $j$ represents the inner southern surface, $T_{j}$ is calculated by integrating the temperature values of the inner surface of the southern façade from the 3D computation of the OVF.

Finally, the long-wave radiative flux balance $q_{j}^{L W}$ is calculated according to Section 4.1.2, but now considering only seven thermal emitters corresponding to the internal specified surfaces. To carry out this computation, the view factors between the inner surfaces of the envelope can be estimated analytically again [46].

On the other hand, the indoor air temperature $T_{z}$ is approximate at each time $t$ by

$$
\begin{aligned}
\frac{d T_{z}(t)}{d t}= & \frac{1}{C_{z}}\left[\sum_{j=1}^{7} h_{j, \text { int }} A_{j}\left(T_{j}(t)-T_{z}(t)\right)+\right. \\
& \dot{m}_{\text {vent }} c_{\text {air }}\left(T_{\text {amb }}(t)-T_{z}(t)\right)+\dot{m}_{\text {inf }} \mathcal{C}_{\text {air }}\left(T_{\text {amb }}(t)-T_{z}(t)+\dot{m}_{\text {sup }} c_{\text {air }}\left(T_{\text {sup }}(t)-T_{z}(t)\right)\right],
\end{aligned}
$$

where $T_{a m b}(t)$ is the exterior air temperature at time $t ; h_{j, i n t}, A_{j}$ and $T_{j}(t)$ are the convective heat transfer coefficient, the area and the temperature at time $t$ of the internal surface $j$ for $j=1, \ldots, 7 ; \dot{m}_{\text {vent }}, \dot{m}_{\text {inf }}$ and $\dot{m}_{\text {sup }}$ are , respectively, the air flux in $[\mathrm{kg} / \mathrm{s}]$ due to ventilation, infiltration and systems providing air at a temperature $T_{\text {sup }}$ and $c_{\text {air }}$ is the specific heat of the air and $C_{z}$ is the heat capacity of the air zone inside the cell.

\subsection{Convective Heat Transfer Coefficients}

For the vertical exterior surfaces, following the recommendations of Mirsadeghi et al. [47] for low rise buildings, the values proposed by Liu and Harris [48]: $h_{c, \text { ext }}=$ $2.08 V_{R}+2.97\left[\mathrm{~W} / \mathrm{m}^{2} \mathrm{~K}\right]$ for windward and $h_{c, e x t}=1.57 V_{R}+2.64\left[\mathrm{~W} / \mathrm{m}^{2} \mathrm{~K}\right]$ for leeward are considered for the vertical façades. For the roof the coefficient value assumed is 
$h_{c, e x t}=8.18+2.28 V_{R},\left[\mathrm{~W} / \mathrm{m}^{2} \mathrm{~K}\right]$, proposed by Hagishima and Tanimoto [49]. In these correlations $V_{R}$ is the wind speed above the roof in $\mathrm{m} / \mathrm{s}$.

The convective heat transfer coefficients for the air cavity are computed by using the Gnielinski correlation [50]. This correlation has often been used to compute the air flow in the frame of turbulent modeling of ventilated façades as in [5].

For the indoor cell, the interior convective heat transfer coefficients are computed by using the correlations proposed by Khalifa and Marshall [51] for vertical walls, floor and ceiling surfaces. These correlations are valid for temperature differences between surface and air less of $5^{\circ} \mathrm{C}$.

\section{Numerical Simulation}

The computational codes were built by using the software FreeFem++ [52], that is a partial difference solver based on the Finite Element Methodology (FEM). As it is well known, the FEM subdivides the domain of computation into smaller domains called elements, where the governing equations are discretized and solved iteratively in time.

The equations for the air flow and the thermal conduction through the OVF are discretized by using the Finite Element Method (FEM). For it, the FreeFem++ software was used to obtain a 3D mesh of tetrahedra of the computational domain and the same software was used to solve numerically the equations.

The spatial discretization of the air governing equations was made by using a $\mathbb{P} 2-\mathbb{P} 1$ finite element approximation for the velocity and pressure and a $\mathbb{P} 1$ approximation for the temperature. For time discretization the method of characteristics was used. The problem of the thermal conduction through the solid elements of the OVF is discretized in space by a $\mathbb{P} 1$ approximation of the temperature whilst a semi-implicit formula is used for time. The thermal conduction through the elements of the test cell envelope that do not belong to the OVF has been done by using a 1D-finite difference approximation in space and an implicit Euler approximation for time. In Appendix B more details about the numerical approach can be found.

In Figure $7 \mathrm{a}$ the 3D tetrahedral mesh of the air chamber used in computations is shown. Figure $7 \mathrm{~b}$ shows the division in zones of the OVF which is later used to describe the results; only the area of the ventilated façade wich faces the wall of the indoor zone is considered to present results, since this is the relevant zone for the heat transmission to the cell indoor. It should be noted that the presence of the window acting as an obstacle causes a lateral displacement of the air flow around the window opening inside the ventilated chamber; thus, the thermodynamic behavior of the air flux is assumed to be the symmetrical in the lateral zones and that is why these zones are called symmetrically.

The climatic values monitored from the weather station were introduced as boundary conditions. In this way, the values of south, north, west, east and horizontal solar irradiation, outdoor temperature, wind velocity and wind orientation were used at each time step in the computations. The sky temperature is not monitored and is therefore computed through the aforementioned Equation (4).

The computation process has two stages or phases. In the first stage, Phase 1 or Preprocess, preliminary calculations were made obtaining a set of data of radiative, geometric and algebraic character to be used in the numerical simulations as previous inputs. So, in this first phase, climatic files are prepared for later use. In the second stage, Phase II, an iteration loop is performed over time, in such a way that for each time step, boundary conditions are updated and then the equations for the air flow thermodynamic and heat conduction at the OVF, as well as the equations for the thermal behavior of the whole cell are solved. 


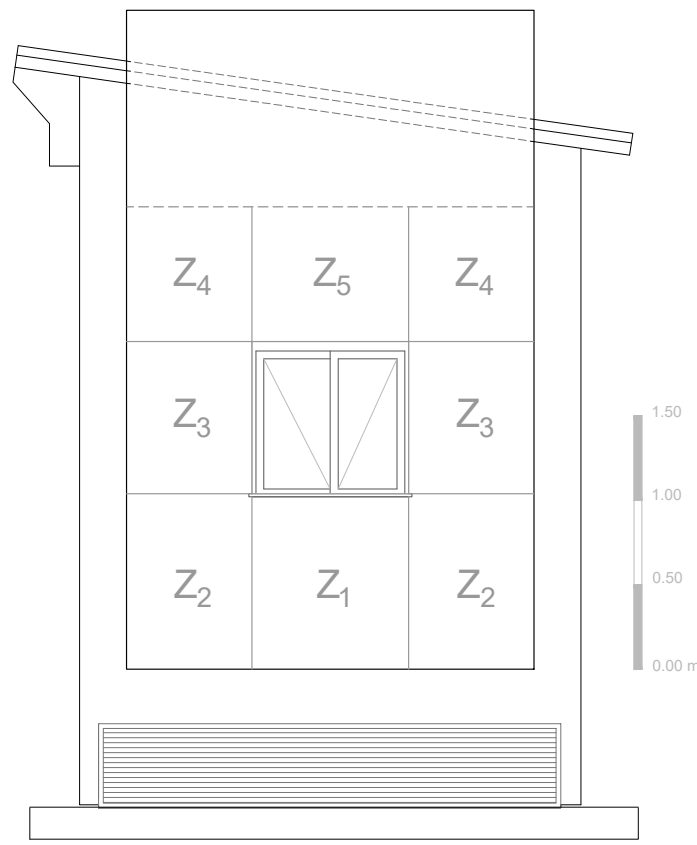

(a)

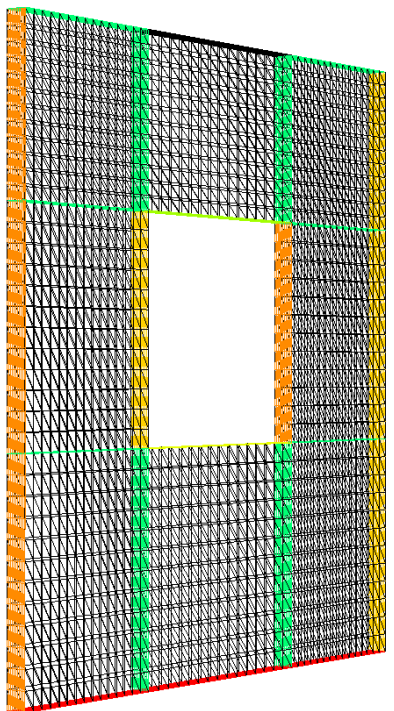

(b)

Figure 7. (a) Considered zones of the OVF; (b) tetrahedral mesh of the air chamber zones with the window opening.

In Figure 8 sketch of the computational code is shown.

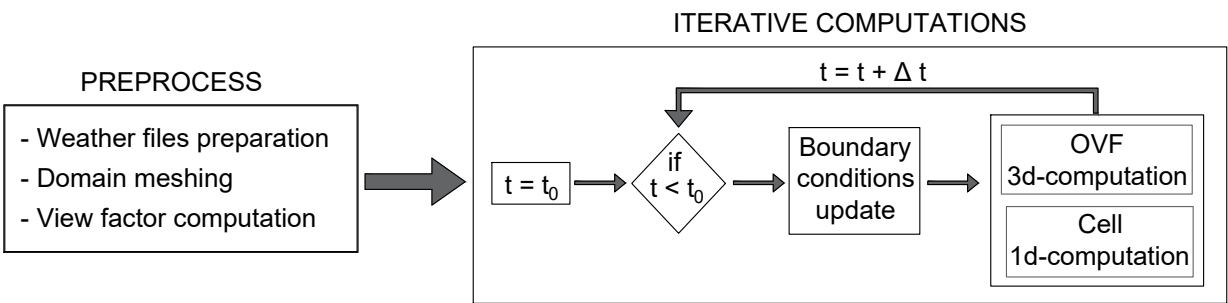

Figure 8. Computational code sketch. $t_{0}$ and $t_{f}$ are the initial and final time for computations.

\section{Results}

\subsection{Measurement Results}

In this section results from the set of monitoring measurements done for open and closed grills opening of the OVF are shown. As said before, for all the time periods shown, the operating protocols for the test cell were closed blind and internal gains, ventilation and HVAC supplies set to zero, therefore, the test cell is considered to be in free floating mode.

First, it should be noted that the presence of the window acting as an obstacle causes a lateral displacement of the air flow around the window opening inside the ventilated chamber; so, sensors are located in such a way that allow to measure the temperature and velocity of the air in the center of the five regions showed in Figure 7 where the air thermodynamic behavior is assumed to be the symmetrical in the lateral zones.

\subsubsection{Inlet Conduct Open}

The trend of the measured air cavity velocity at the ventilated façade is shown in Figure 9 for five minutes measurements throughout a summer day, 5 July 2021.

In a more compact way Figure 10a,b show the hourly values of air the velocity at the ventilated chamber for a winter and a summer day, respectively.

From the observation of these figures, it can be seen that the zones described in Figure 7 are characterized, regarding air flow movement, by different patterns that can be described coarsely as follows: in zone 1, the rising air heated by the channel surfaces and the air 
entering the opening are blocked by the window casement, in turn, low air velocities are expected in this zone, being the air forced to rise around the window and to income in zone 2 ; in zone 2, the air heated by the channel surfaces and the incoming air from the opening can ascend freely without obstacles toward zone 3, reaching higher velocities than in zone 1 , although near the lower window corners the rising air is affected by the air entering from zone 1; in zone 3 an acceleration of the air flux can be expected due to the air from zone 2 and 1, that causes an increase in air pressure at this zone; on the contrary, in zone 4 air can both exit through the upper zone and partly move toward zone 5, which can cause decompression and an associated decrease in flow velocity; finally, in zone 5, the absence of air flowing from the bottom, so, though the heating of the channel walls should force the air to rise, the lack of incoming air from below is expected to produce an stagnation zone.

Figures 9 and 10 show the effect of solar radiation on the air velocities in the ventilated cavity. In both figures, a general decrease of air velocities is foundin all the zones of the ventilated chamber when solar radiation decreases. However, ambient temperature also influences air velocity. Thus, in Figure 10a,b, an increase in ambient temperature and an increase in air velocity in the cavity can be observed after noon.

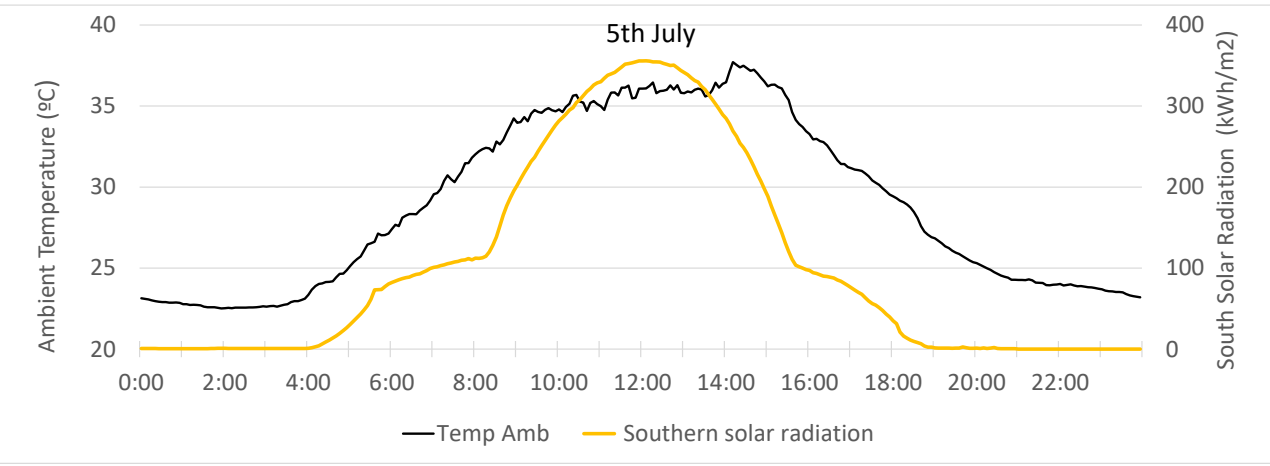

(a)

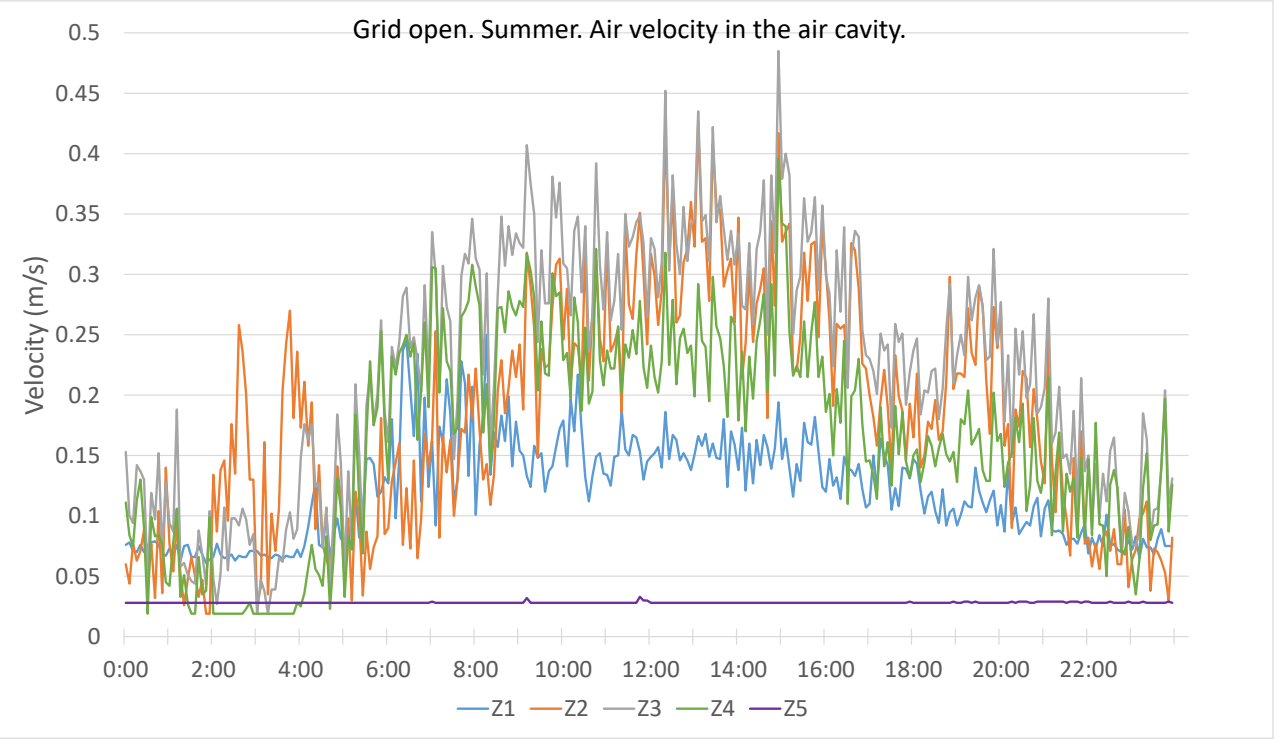

(b)

Figure 9. Open ventilation grills, 5 July 2021: (a) south solar radiation and ambient temperatures; (b) trend of the measured air cavity velocities at the ventilated façade. 


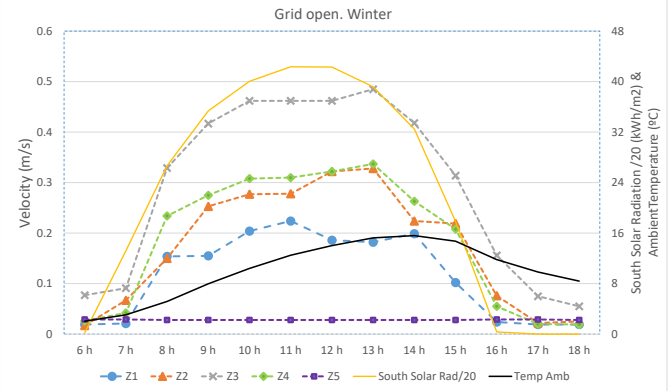

(a)

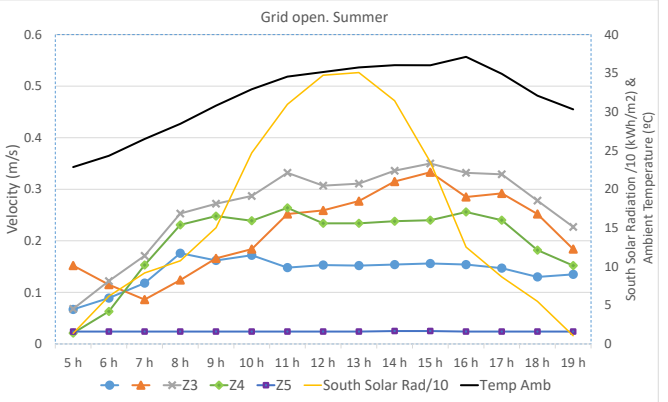

(b)

Figure 10. Open ventilation grills. Trend of the measured air cavity velocity: (a) for a winter day (14 January 2021); (b) for a summer day (5 July 2021). South solar radiation and ambient temperatures are reported.

On the other hand, as usually is found at the OVFs behavior, the air velocity increases as the values of the solar radiation on the façade increase, being this effect more evident at zones of free air movement again. It is noteworthy that solar radiation has a stronger impact on air speed in zones 2, 3 and 4, where air flows unimpeded, while speed in zone 1 is less affected and in zone 5 speed is below sensor sensitivity limit. This effect of the solar radiation on air speed can be observed too by comparing the velocity of each zone in winter and summer. Thus, Figure 10a,b show how in winter, when the solar radiation that hits the façade is higher, the speeds in the ventilated chamber are also higher. Likewise, the velocity patterns for the different zones commented above, are clearly observed in the figures.

Figure 11 show the temperature evolution for a winter and a summer day, respectively, at the sensors positions shown in Figure 3, that is, in the center of every zone pictured in Figure 7 . On the other hand, Figure $11 \mathrm{a}, \mathrm{c}$ show the temperatures measured in the inner surface of the outer slab, that is, the surface facing the air gap, whilst Figure 11b,d show the temperatures measured on the surface of the inner wall facing the cavity. The sensors are named according to the zone nomenclature entered previously.

The vertical southern global solar radiation and the outdoor ambient temperature measured at the meteorological station are also displayed in the figures.

Slight differences can be appreciated between the temperatures for winter and summer conditions. Thereby, although the solar radiation reaching the façade is higher in winter, the surfaces temperatures are lower due to the lower values for the outdoor air temperature entering the ventilated channel and the cooling produced on the exterior coating by the convection with lower temperatures as well as by the radiative exchange with sky temperature, usually lower than in summer. On the internal face of the outer layer, it can be observed that at the center of zones 2 and 3, the temperatures are at their lowest due to the effect of the cold air entering the channel that flows freely in these zones. The temperatures in zones 1, 4 and 5 are the highest although for different reasons. In zones 1 and 5, the low air velocity due to the reasons explained before, results in a lower convective heat transferred and in turn, in lower cooling of the surfaces. Meanwhile, in zone 4 the air has had a longer journey through the canal, which raises its temperature. This, together with the slower speed in this area, produces a lower cooling effect on the channel walls.

On the surface of the inner wall facing the air channel, these effects are lessened, probably due to the effect of the heat conduction from the indoor space; however, in zone 2, where the air flows more freely and is closer to the inlet it can be observed that the surface has the lower temperatures. Likewise, it can be observed than at the center of the day, when solar radiation is higher, the temperatures of this surface are lower than those of the outer slab ones, while at night they are higher, according with a lower influence of solar gain and radiative and convective cooling, respectively, on the exterior wall surface. 


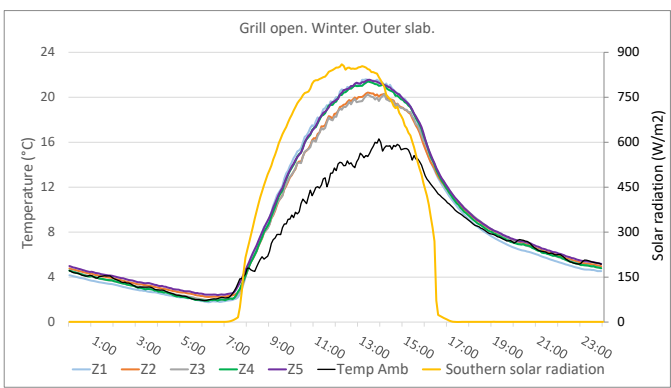

(a)

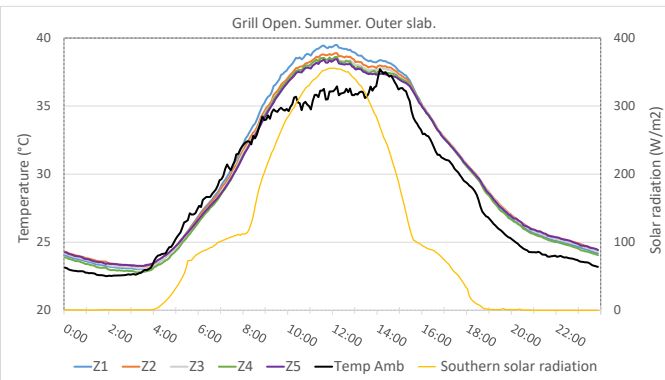

(c)

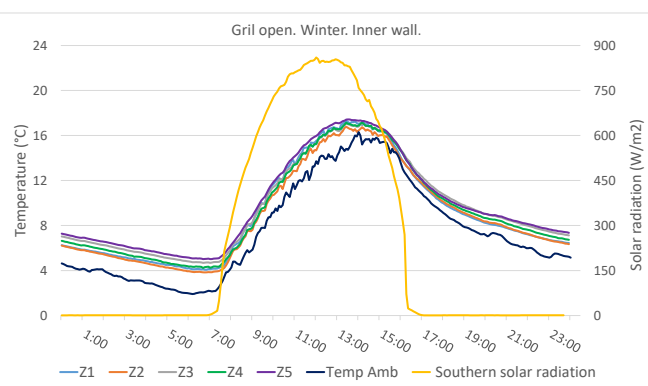

(b)

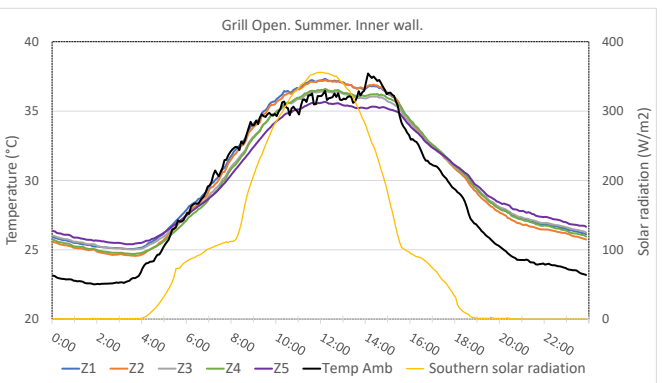

(d)

Figure 11. Open ventilation grills. Evolution of the measured temperatures of the air cavity surfaces for a winter day (14 January 2021): (a) exterior slab, (b) inner wall; and a summer day (5 July 2021): (c) exterior slab, (d) inner wall. South solar radiation and ambient temperatures are reported.

In summer, on the internal surface of the outer layer, the higher temperatures are found in zone 1 , according to the lower velocities at this area, while in zone 3 , where the air velocity is higher, the surface temperatures are lower due to the increase in convective cooling. On the other hand, for the wall surface, the temperatures are some more homogenous, although in daylight slightly higher values can be observed again in zone 1, whereas now the zone 5 has the lower values. Finally, Figure 11 shows that the surfaces temperatures are lower at night and its variation range are lower than for daylight, facts previously observed in the literature [8].

By comparing the interior channel surfaces temperatures for winter and summertime, it can be concluded that solar radiation is a conditioning factor for the temperatures behavior. However, outdoor temperature also leads to an increase in air cavity surfaces temperatures in such a way that the predominant factor for the increasing of air cavity surfaces depends on each weather station. This way, in winter with higher solar radiation on the OVF, the interior surfaces of the channel have lower temperatures than in summer where solar radiation on the façade is lower but outdoor temperature is higher.

Figure 12 shows the measured temperature trends for zones 2, 3 and 4 for a winter day (14 January 2021) at the different layers conforming the OVF for daylight hours with different outdoor temperature and south vertical solar radiation. As can be noted in the temperature profiles, there is an increase of the air temperature in the air cavity as the channel height where the temperature is measured increases. Thus, both on the surfaces and in the air of the ventilated chamber, the lower temperatures are found in zone 2, followed by zone 3 whilst the higher ones are in zone 4 . This temperature behavior is typical for OVFs as it has been often reported in the literature [8,30].

The interior temperatures of the wall layers are not reported because these layers were not monitored. 


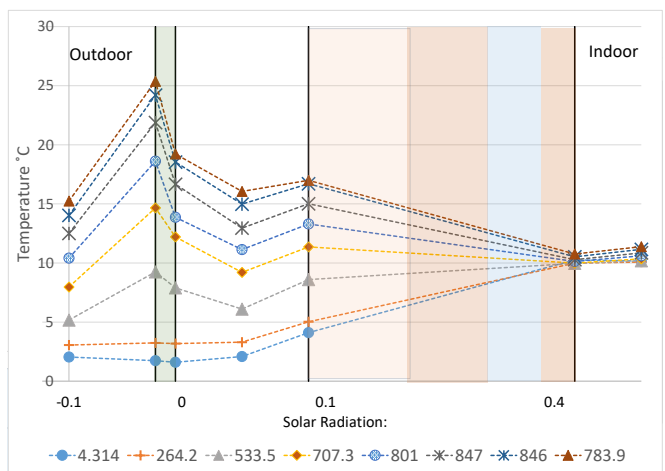

(a)

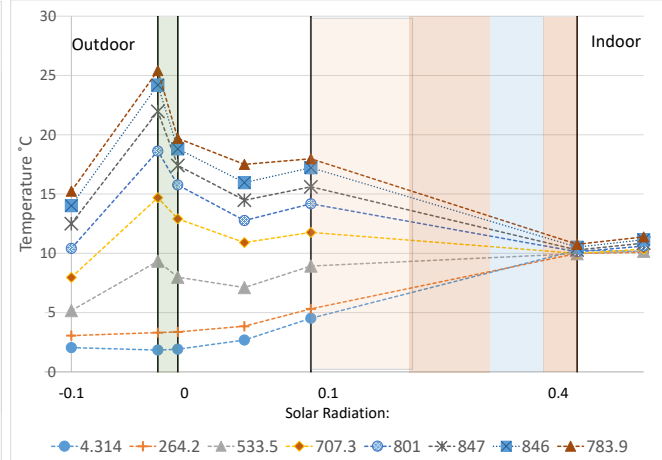

(b)

Figure 12. Open ventilation grills. Trend of measured temperature in the different layers of the southern ventilated façade for daily hours with different solar radiation and temperature values under winter conditions (14 January 2021), for: (a) Zone 2; (b) Zone 4.

\subsubsection{Inlet Conduct Closed}

In this case, the air flux in the air cavity is not affected by the air inlet from the outside and only natural convection produced by the heating of the air cavity surfaces is present; the main effect of this is that air velocities in the air cavity are lower than for the case of the grid open, Figures 13 and 14, and temperatures are higher due to the double effect of reduction of the convection and no inlet of air, usually at lower temperatures.

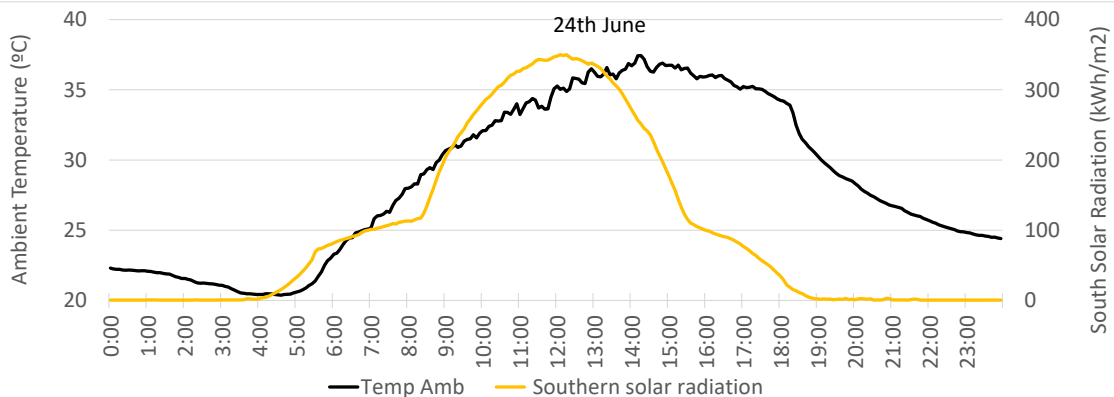

(a)

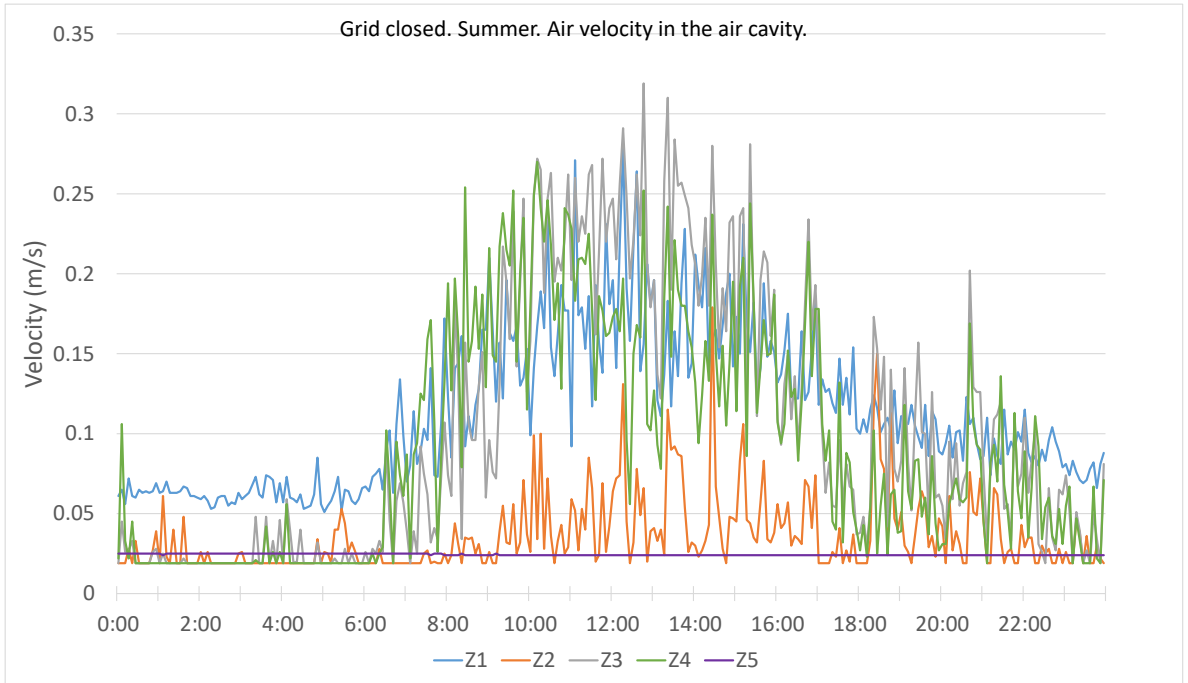

(b)

Figure 13. Closed ventilation grills, 24 June 2021: (a) south solar radiation and ambient temperatures; (b) trend of the measured air cavity velocities at the ventilated façade. 


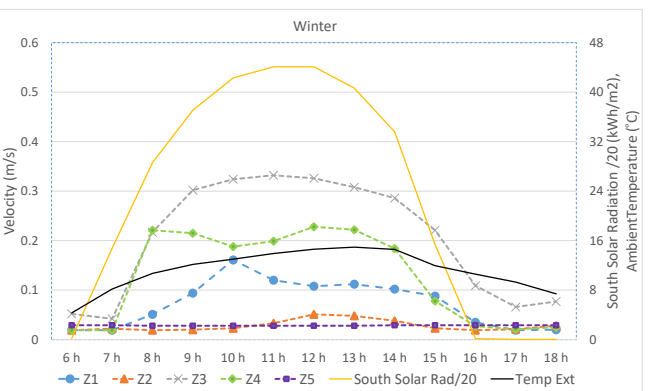

(a)

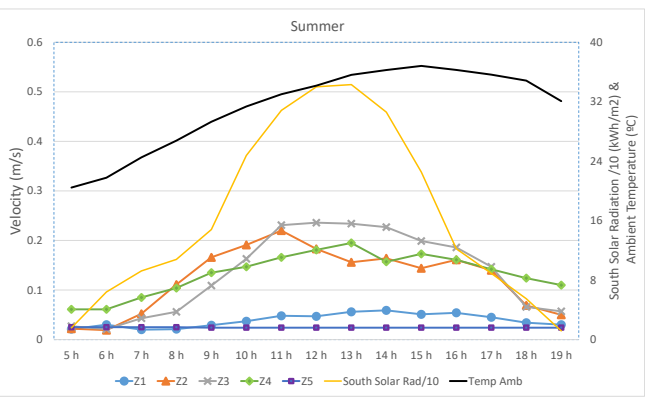

(b)

Figure 14. Closed ventilation grills. Trend of the measured air cavity velocity: (a) for a winter day (2 January 2021); (a) for a summer day (24 June 2021). South solar radiation and ambient temperatures are reported.

The trend of the measured air cavity velocity at the ventilated façade with inlet openings closed is showed in Figure 13 for five minutes measurements throughout a summer day, 24 June 2021, and in Figure 14a,b are shown for hourly values for a winter day and a summer day, respectively. The greatestr difference with respect to the case of inlet grids open is the lower values of the velocities, which are now roughly half for similar weather conditions. Again, the highest rate values are found at zone 3 followed by the values in zone 4 .

Figure 15 shows the temperature evolution for a winter and a summer day, respectively, for a closed inlet. Figure 15a,c show the temperatures measured in the inner surface of the outer slab and Figure 15b,d correspond to the measured temperatures of the inner wall facing the cavity.

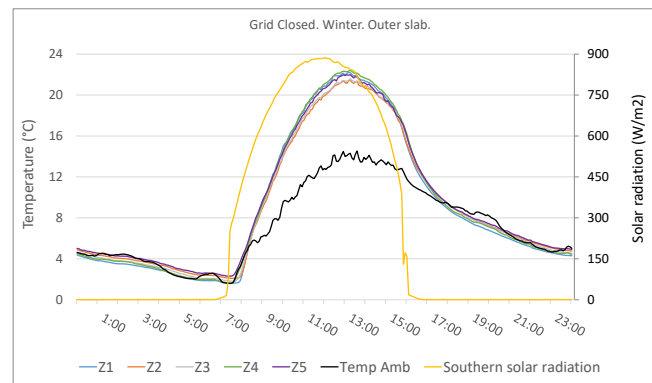

(a)

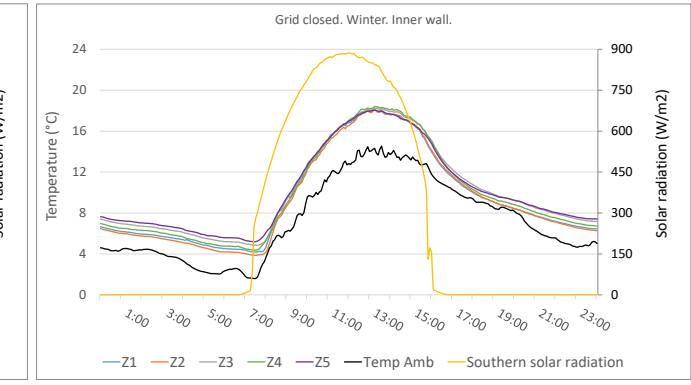

(b)

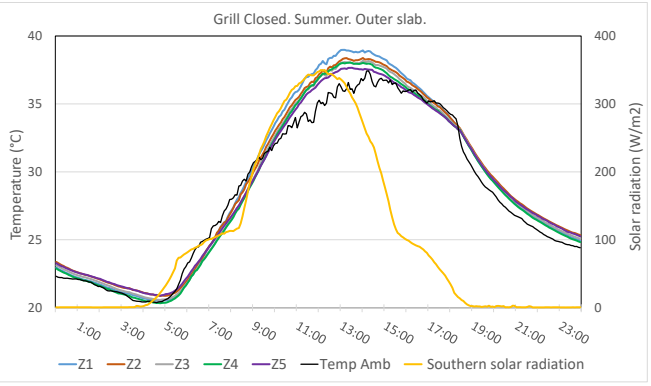

(c)

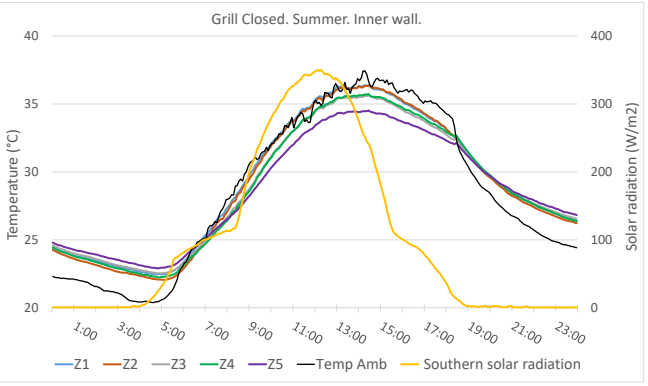

(d)

Figure 15. Closed ventilation grills. Evolution of the measured temperatures of the surfaces in the air cavity for: a winter day (3 January 2021), (a) exterior slab, (b) inner wall; a summer day (24 June 2021), (c) exterior slab, (d) inner wall. South solar radiation and ambient temperatures are reported.

The vertical southern global solar radiation and the outdoor temperature measured at the meteorological station are also displayed in the figures.

As for the case of the inlet conduct open, the temperatures of the interior surfaces of the air cavity increase when solar radiation and outdoor temperature increases, and again 
it can be observed that the outer slab exhibits a greater dependence on the ambient factors than the inner wall.

Comparing the temperatures for the closed inlet conduct to the temperatures for the inlet conduct open, it can be observed that in winter, when outdoor air is colder than in summer, the difference between the temperatures of the interior surface of the exterior coating and the outdoor temperature is higher for the inlet conduct closed, due obviously to because no air enters from the outside. The same can be observed for the surface of the inner wall. In summer the same pattern can be observed, although now, the difference is less pronounced because of the higher outdoor temperatures. This suggests that in winter the OVF with inlet conduct closed can reduce the heat loss from the indoor. This fact will be analyzed in Section 7.

\subsubsection{Comparison of Operative Temperatures}

In this section, the effect of the ventilated façade on the indoor temperatures are analyzed for three time periods in winter, spring, and summer. For it, the operative temperature of the cell with the OVF, Cell 1, and the operative temperature of the cell with the UVF, Cell 3, are compared considering the inlet conduct both open and closed.

In Figure 16a the operative temperatures are shown for the case of grid open in winter. As can be observed, the temperature for Cell 3 reaches higher values in daylight, showing its strong dependence on solar gain. On the contrary, the temperature for Cell 1, although raises too at daylight, has lower values, according to the to the shielding against solar radiation provided by the OVF. At night, the temperatures for Cell 3 are a little lower or almost equal to the temperature for Cell 1, showing that the heat stored at walls of Cell 3 is enough to compensate for the higher heat loss during night. In Figure $16 \mathrm{~b}$ the operative temperatures are shown for the case with closed grill. Now, it can be noted that the operative temperatures in Cell 1 have a smaller range of variation and more centered behavior with respect to the temperature of Cell 3. Thus, the difference in temperatures in daylight is lower between Cell 1 and Cell 3, while at night Cell 1 displays higher temperatures than Cell 3 , thereby exhibiting the role of the sealed air cavity as an insulating layer. Furthermore, it is noteworthy to observe in Figure 16b that when the value of solar radiation is low, the temperatures of Cell 1 and Cell 3 are very close, which highlights how the greatest difference between OVF and UVF is due to the effect of the outer slab offering protection against solar radiation.

In Figure 16c,d, the operative temperatures are shown for a springtime interval. Now, the outdoor temperature is moderately warm, with values higher than those typical for this time of year in the city of Seville. It can be observed that now the OVF display higher values of the operative temperatures for both cases of grill open and closed. In the case of the grid open, Figure 16c, it can be observed that the low values of the solar radiation reaching the façade result in lower values for Cell 3 than for Cell 1, and only for the second day of this period, when solar radiation is higher, Cell 3 reaches higher values than Cell 1, demonstrating again the role of the OVF as a shield from solar radiation. Likewise, for the case with the grill closed, Figure 16d, a similar pattern can be observed, although now, the difference between the operative temperatures is smaller.

Again, it can be seen that when solar radiation is high, the OVF with grid open has lower values in daylight, while at night Cell 3 has lower temperatures, which demonstrates the difficulty of the OVF to dissipate the stored heat. However, for low radiation values, Cell 3 has lower temperatures in daylight according to a higher heat loss due to its thermal insulation, weaker than that of Cell 1.

For the case of grid closed, the Cell 1 almost always displays higher operative temperatures than Cell 3. For this springtime interval, the dissipation of stored heat is more efficient for the UVF that for the OVF which has an oven effect, which for high outdoor temperatures this can lead to situations of overheating and thermal discomfort.

Figures $16 \mathrm{e}, \mathrm{f}$, show the operative temperatures for a summertime interval. For both periods, solar radiation values are similar and the ambiance temperature is in general a 
little higher in July than in June. Now, it can be observed that the impact of the solar radiation produces a more higher values of the operative temperature for the Cell 3 than for the Cell 1. It can be highlighted that for the case of the grill open, the difference between the operative temperatures is lower than for the case of the grill closed. This may be due to the fact that when the temperature of the air incoming in the ventilated channel is high, the OVF is less efficient to reduce the heat flux, and thus, when the grill is closed this intromission of the hot air inside de chamber is avoid and the OVF works in a better way to reduce the heat flux to the cell indoor.

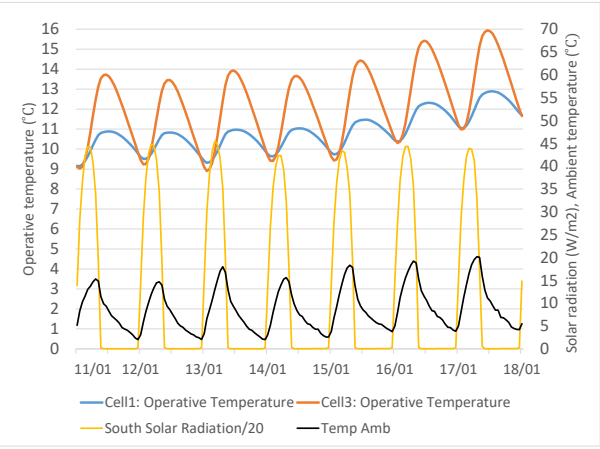

(a)

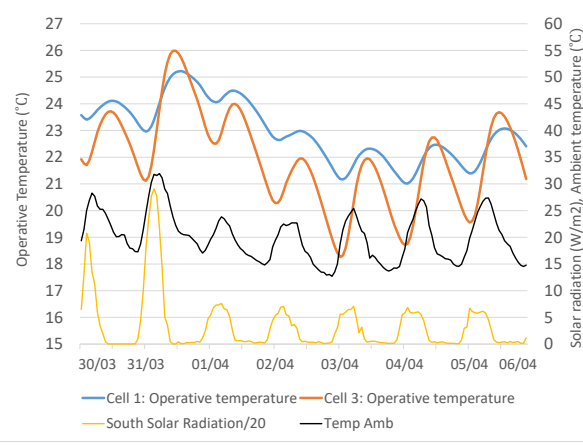

(c)

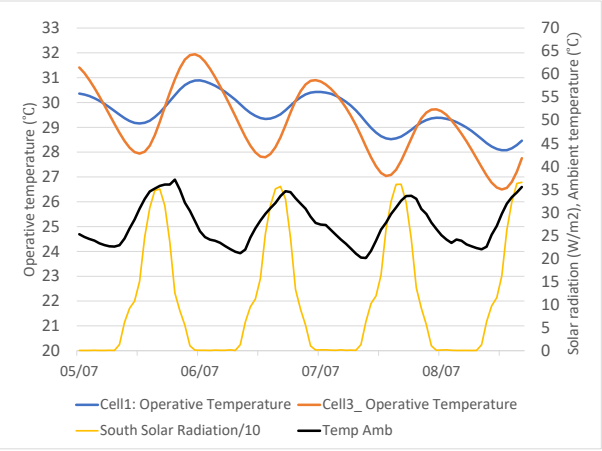

(e)

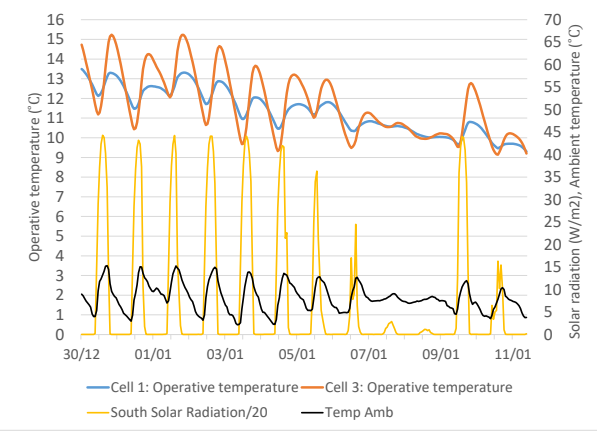

(b)

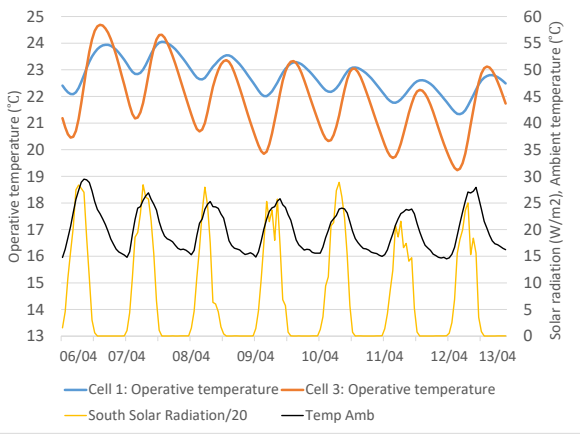

(d)

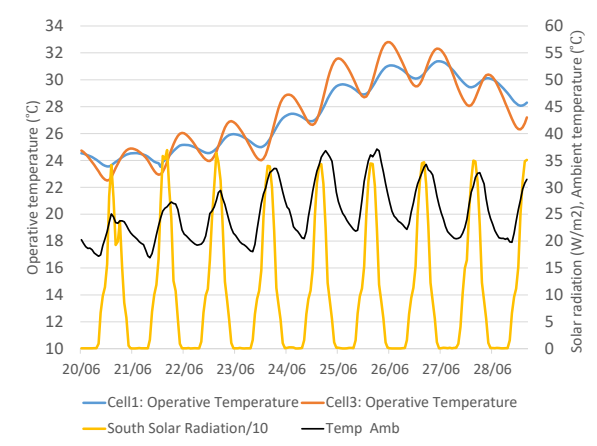

(f)

Figure 16. Comparison of the operative temperatures of Cell 1 (OVF) and Cell 3 (UVF). Wintertime: (a) grill open (11 January to 18 January 2021), (b) grill closed (29 December 2020 to 5 January 2021). Springtime: (c) grill open (30 March to 6 April 2021); (d) grill closed (6 to 13 April 2021). Summertime: (e) grill open (5 to 8 July 2021); (f) grill closed (20 to 28 June 2021).

On the other hand, it can be observed that in general, the dissipation of stored heat is more efficient at night for the UVF that for the OVF that has an oven effect, which for high outdoor temperatures can lead to situations of overheating and thermal discomfort 
at night; in this case, the use of ventilation could be suitable to take advantage of lower outdoor temperatures at night.

\subsection{Simulation Results}

This section presents some representative results of the simulation model for the different dates considered. Validation results and comparisons with monitored data are also shown.

\subsubsection{Air Flow Simulation in the OVF}

Figure 17a-d show the velocity field for the open grill case at $12 \mathrm{~h}$ on 14 January 2020. The velocity field is plotted at four cutting planes of the air cavity parallel to the outer slab and the inner wall. These planes are located at a distance of $0.02 \mathrm{~m}$ Figure $17 \mathrm{a}, 0.04 \mathrm{~m}$ Figure $17 \mathrm{~b}, 0.06 \mathrm{~m}$ Figure $17 \mathrm{c}$ and $0.08 \mathrm{~m}$ Figure $17 \mathrm{~d}$ from the outer slab.

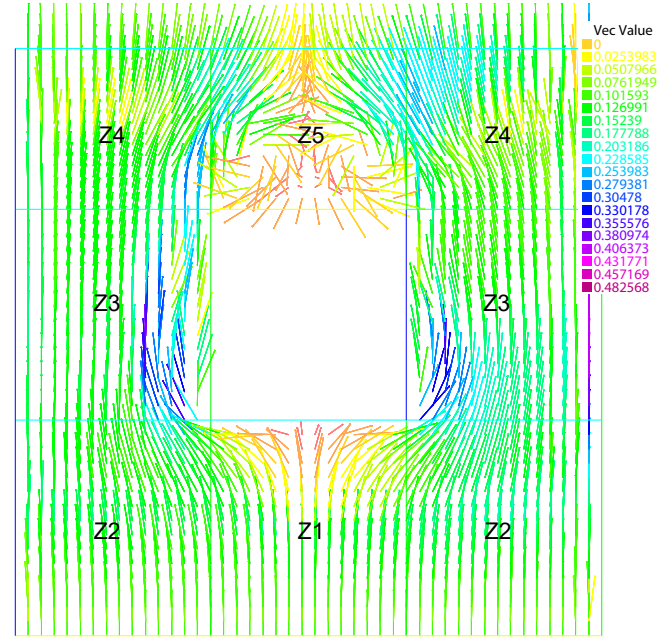

(a)

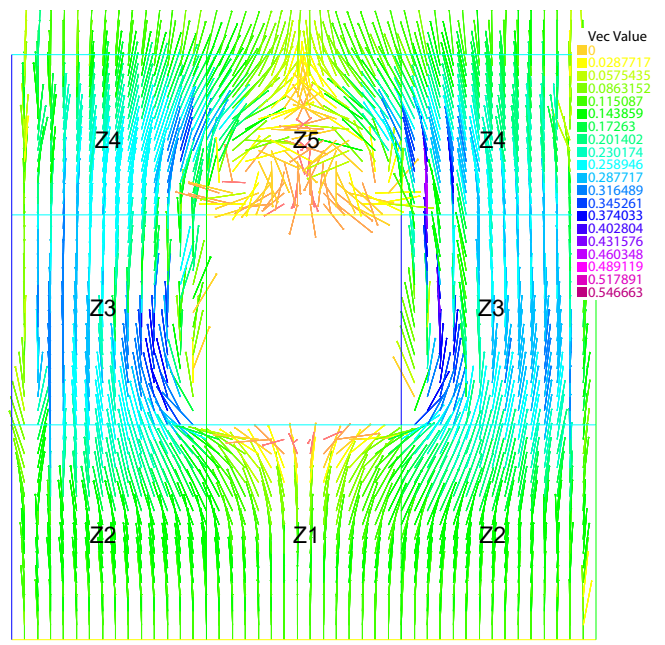

(c)

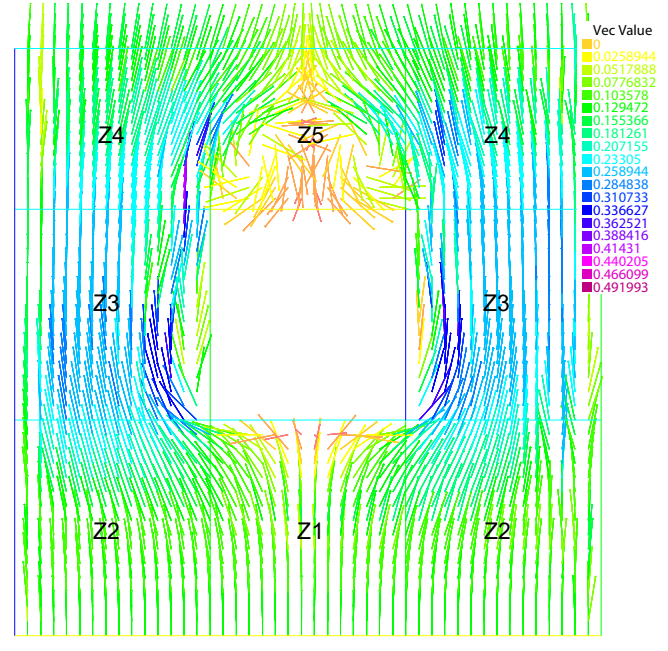

(b)

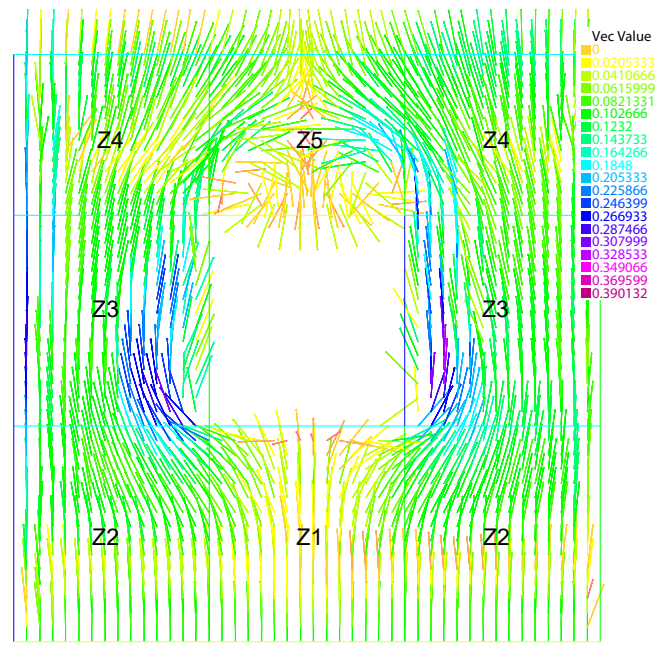

(d)

Figure 17. Velocity field of the air flow in the ventilated cavity of Cell 1 (OVF) for: (a) cutting plane at $0.02 \mathrm{~m}$; (b) cutting plane at $0.04 \mathrm{~m}$ from the outer slab; (c) cutting plane at $0.06 \mathrm{~m}$; (d) cutting plane at $0.08 \mathrm{~m}$ from the outer slab.

It can be observed in the figures that air ascends throughout the ventilated cavity following the patterns discussed in Section 6.1.1. In short, the air rises without obstacles along zones 2, 3 and 4 as heat by convection from the outer slab and the inner wall being 
exhausted through top opening whilst exterior air enters from grid opening at the bottom of the OVF. In zone 1, the rise of the air is hampered by the window, resulting in lower velocity in this zone. At the same time, air from this zone enters in zone 3 through the corners of zone 2 next to the window which causes an increase in velocities in the region of zone 3 next to window. In zone 4 , the decompression caused by the exit of the air towards the outside and toward zone 5 causes a decrease of the air velocity, fact that has been described in the literature [8]. Finally in zone 5 there is an area up the window with low air velocities and where it can be observed that the air forms two small recirculation vortices in the area nearest to the window.

Figure 18 shows the temperature at the same cutting planes that are used for the velocity field. As can be noted, the exterior air enters through the bottom openings gaining heat by convection from the outer slabs and the inner wall as it rises along the ventilated cavity. It can be highlighted that because at this hour there is a high solar radiation the outer slab reaches a higher temperature that the inner wall and so, the air in the cutting plane nearest to the outer slab, Figure 18a exhibits the highest temperatures, that are progressively decreasing, Figure 18b,c, until taking the lowest values in the section closest to the wall Figure 18d.

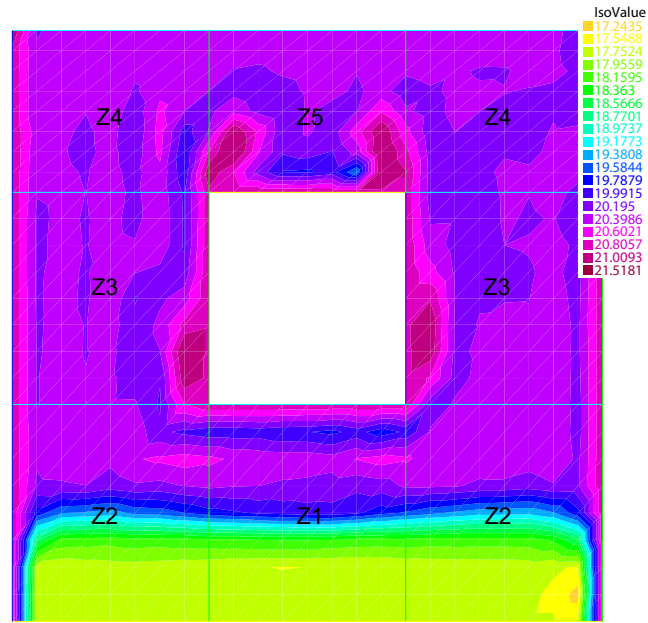

(a)

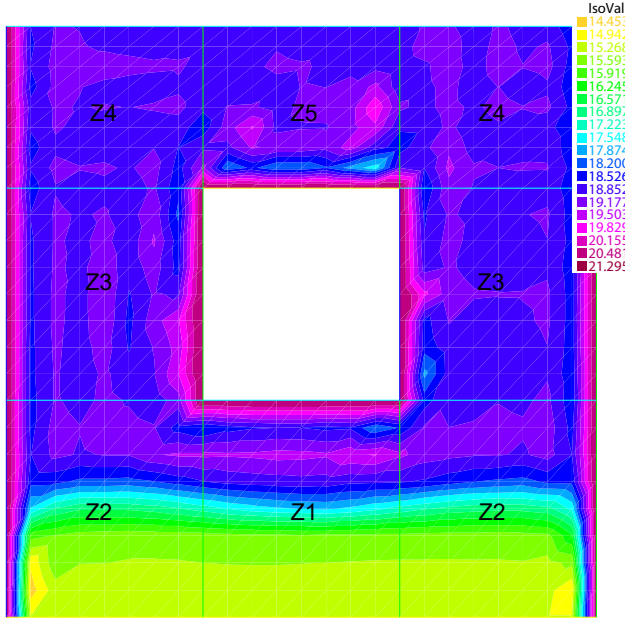

(c)

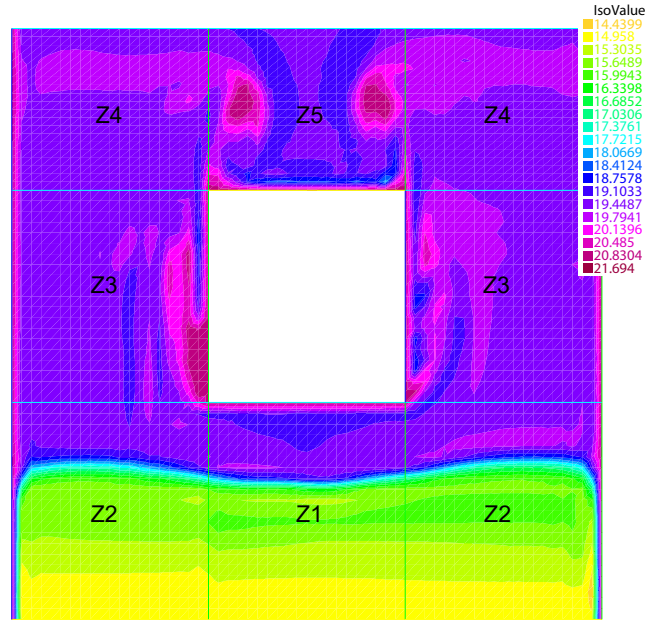

(b)

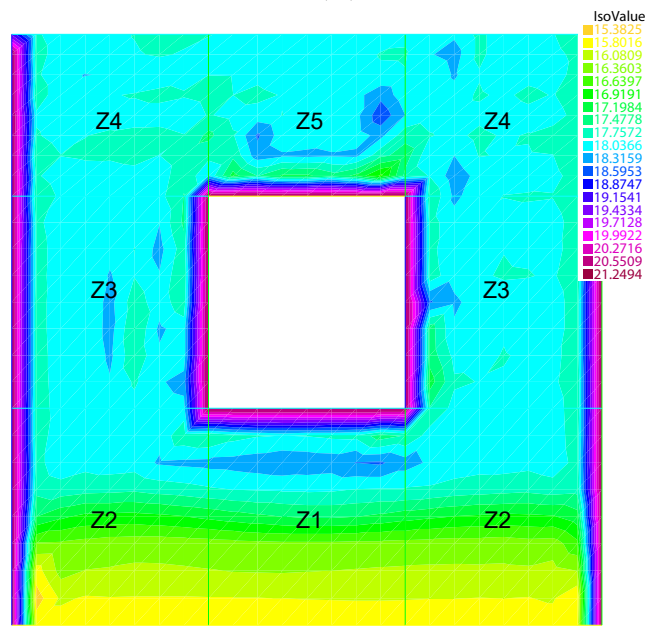

(d)

Figure 18. Temperatures of air in ventilated cavity of Cell 1 (OVF) in: (a) cutting plane at $0.02 \mathrm{~m}$; (b) cutting plane at $0.04 \mathrm{~m}$; (c) cutting plane at $0.06 \mathrm{~m}$; (d) cutting plane at $0.08 \mathrm{~m}$ from the outer slab.

From this velocity and temperature behavior the three-dimensional nature of the air flow thermodynamic in the air cavity can be clearly established. 


\subsubsection{Model Validation: Statistical Indices}

In order to perform the model validation, measured local weather data for the intervals of time of the different described protocols were used. These weather data included ambient air temperature and relative humidity, global radiation for vertical South, East, West, North and horizontal sides and wind speed and direction. By using the weather data as input data in the simulation model, the hourly values of the temperatures of each surface of the OVF and the velocities of the air flow in the ventilated channel of the OVF were calculated, as well as the temperatures of the internal surfaces and indoor air of the test cell.

First the temperatures of the air in the ventilated cavity and at the surfaces conforming the cavity were checked by comparing the measured values and the ones computed by the numerical model. Then, the measured values of the wall internal surface temperature and the interior cell air temperature were compared too with the ones predicted by the model. The validation process was performed for the three different time intervals mentioned above: winter, early spring and late spring of 2020. For these intervals of time, the two cases of grid openings closed and open were checked.

To perform the validation analysis, we follow the widely recognized guidelines and methodologies to assess the accuracy of BES models established by ASHRAE Guideline 142014, the International Performance Measurement and Verification Protocol (IPMVP) and the Federal Energy Management Program (FEMP). These agencies recommend considering a model is validated when the model outputs meet the indices shown in Table 5.

Table 5. Model validation criteria of ASHRAE Guideline-12, FEMP and IPMVP.

\begin{tabular}{lccc}
\hline & \multicolumn{3}{c}{ Model Validation Criteria for Hourly Data } \\
\hline Index & AHSRAE Guidelines & FEMP & IPMVP \\
\hline NMBE $(\%)$ & $\in[-10,10]$ & $\in[-10,10]$ & $\in[-5,5]$ \\
$C V(R M S E)(\%)$ & $<30$ & $<30$ & $<20$ \\
\hline \multicolumn{4}{c}{ Model recommended value } \\
\hline Index & AHSRAE Guidelines & FEMP & IPMVP \\
\hline$r^{2}$ & $>0.75$ & $>0.75$ & - \\
\hline
\end{tabular}

For the air temperature in the ventilated channel, when the grid is open, the NMBE indicator ranges in winter from a minimum of $-1.85 \%$ for zone 2 to a maximum of $-8.47 \%$ for zone 5 , in spring it ranges from $-2.1 \%$ for zone 2 to a maximum of $-8.11 \%$ for zone 1 and in summer it ranges from $-2.3 \%$ for zone 4 to a maximum of $8.66 \%$ for zone 5 . For the grid closed case, the NMBE indicator ranges in winter from a minimum of $-3.92 \%$ for zone 4 to a maximum of $-8.97 \%$ for zone 5 , in spring it ranges from $-2.01 \%$ for zone 2 to a maximum of $-7.89 \%$ for zone 1 and in summer it ranges from $-1.39 \%$ for zone 4 to a maximum of $8.89 \%$ for zone 5 .

Regarding the $\mathrm{CV}$ (RMSE) indicator, for the open grid case in winter it ranges from a minimum of $6.11 \%$ for zone 2 to a maximum of $14.12 \%$ for zone 5 , in spring it ranges from $4.36 \%$ for zone 4 to a maximum of $11.31 \%$ for zone 1 , and in summer it ranges from $7.96 \%$ for zone 4 to a maximum of $13.12 \%$ for zone 5 . For the grid closed case, the CV(RMSE) indicator ranges in winter from a minimum of $5.94 \%$ for zone 4 to a maximum of $13.66 \%$ for zone 5 , in spring it ranges from $7.03 \%$ for zone 2 to a maximum of $12.91 \%$ for zone 1 and in summer it ranges from $5.57 \%$ for zone 4 to a maximum of $13.97 \%$ for zone 5 .

In Table 6, he minimum, maximum and mean value of the statistical indicators NMBE, $C V(R M S E)$ and $r^{2}$ are shown for the temperatures of the air inside the channel and the temperatures of the channel surfaces calculated by the numerical model for the OVF using the monitoring data as benchmark. The analyzed variables are the measured and computed values in the five zones described above of the air temperature in the ventilated cavity, the surface temperatures of the outer slab and the external surface of the internal wall facing the air cavity of the OVF. Then, once the values of NMBE, CV (RMSE) and $r^{2}$ are computed 
for the set of calculated and measured variables, the minimum, maximum and mean value of these indicators for air and surfaces are reported separately in Table 6. Comparison of the temperatures of the indoor air and the internal surface of the southern wall for Cell 1 are reported in the next section.

Table 6. Values of the statistical indicators for temperature.

\begin{tabular}{|c|c|c|c|c|c|c|}
\hline \multirow[b]{2}{*}{ Index } & \multicolumn{3}{|c|}{ Cavity Air } & \multicolumn{3}{|c|}{ Cavity Surfaces } \\
\hline & Minimum & Maximum & Mean & Minimum & Maximum & Mean \\
\hline & \multicolumn{6}{|c|}{ Winter. Grill open } \\
\hline NMBE (\%) & -1.85 & -8.47 & -5.65 & -0.0095 & 1.3821 & 1.2093 \\
\hline CV $(R M S E)(\%)$ & 6.11 & 14.12 & 9.6729 & 2.6434 & 2.8387 & 2.6800 \\
\hline \multirow[t]{2}{*}{$r^{2}$} & 0.9416 & 0.8698 & 0.9081 & 0.9716 & 0.9502 & 0.9766 \\
\hline & \multicolumn{6}{|c|}{ Winter. Grill closed } \\
\hline NMBE (\%) & -3.92 & -8.97 & -2.5390 & -2.3274 & 0.3809 & -1.1434 \\
\hline$C V(R M S E)(\%)$ & 5.94 & 13.66 & 8.6819 & 3.5342 & 3.1046 & 3.2593 \\
\hline \multirow[t]{2}{*}{$r^{2}$} & 0.9628 & 0.8961 & 0.9031 & 0.9634 & 0.9562 & 0.9877 \\
\hline & \multicolumn{6}{|c|}{ Spring. Grill Open } \\
\hline NMBE (\%) & -2.1 & -8.11 & -6.23 & 1.3229 & -1.3965 & 1.5410 \\
\hline$C V(R M S E)(\%)$ & 7.36 & 11.31 & 9.3498 & 2.1198 & 2.872 & 2.0103 \\
\hline \multirow[t]{2}{*}{$r^{2}$} & 0.9101 & 0.7901 & 0.8488 & 0.8901 & 0.9105 & 0.8970 \\
\hline & \multicolumn{6}{|c|}{ Spring. Grill Closed } \\
\hline NMBE (\%) & -2.38 & -7.89 & -0.2647 & -0.1146 & -0.0615 & -0.0094 \\
\hline$C V(R M S E)(\%)$ & 7.03 & 12.91 & 10.89429 & 1.9780 & 1.8388 & 1.8357 \\
\hline \multirow[t]{2}{*}{$r^{2}$} & 0.9156 & 0.8291 & 0.8797 & 0.9032 & 0.9198 & 0.9286 \\
\hline & \multicolumn{6}{|c|}{ Summer. Grill Open } \\
\hline NMBE $(\%)$ & -2.3 & -8.66 & -6.23 & 1.3229 & -1.3965 & 1.5410 \\
\hline CV $(R M S E)(\%)$ & 8.96 & 15.12 & 12.3498 & 2.1198 & 2.872 & 2.0103 \\
\hline \multirow[t]{2}{*}{$r^{2}$} & 0.9101 & 0.8692 & 0.8808 & 0.8901 & 0.9105 & 0.8970 \\
\hline & \multicolumn{6}{|c|}{ Summer. Grill Closed } \\
\hline NMBE (\%) & -1.39 & 8.89 & -0.2647 & -0.1146 & -0.0615 & -0.0094 \\
\hline CV $(R M S E)(\%)$ & 8.57 & 13.97 & 10.89429 & 1.9780 & 1.8388 & 1.8357 \\
\hline$r^{2}$ & 0.9156 & 0.8239 & 0.8597 & 0.9032 & 0.9198 & 0.9286 \\
\hline
\end{tabular}

For the air velocity in the ventilated channel, when the grid is open, the NMBE indicator ranges in winter from a minimum of $4.82 \%$ for zone 2 to a maximum of $8.91 \%$ for zone 5 , in spring it ranges from $-3.99 \%$ for zone 2 to a maximum of $-7.91 \%$ for zone 5 and in summer it ranges from $4.41 \%$ for zone 2 to a maximum of $9.50 \%$ for zone 5 . For the grid closed case, the NMBE indicator ranges in winter from a minimum of $3.99 \%$ for zone 1 to a maximum of $8.53 \%$ for zone 3 , in spring it ranges from $4.07 \%$ for zone 1 to a maximum of $6.78 \%$ for zone 5 and in summer it ranges from $3.95 \%$ for zone 1 to a maximum of $8.03 \%$ for zone 3.

Regarding the $\mathrm{CV}$ (RMSE) indicator, for the open grid case in winter it ranges from a minimum of $15.67 \%$ for zone 2 to a maximum of $22.80 \%$ for zone 5 , in spring it ranges from $11.71 \%$ for zone 2 to a maximum of $22.30 \%$ for zone 5 , and in summer it ranges from $17.08 \%$ for zone 2 to a maximum of $23.39 \%$ for zone 5 . For the grid closed case, the CV(RMSE) indicator ranges in winter from a minimum of $14.39 \%$ for zone 1 to a maximum of $21.09 \%$ for zone 3 , in spring it ranges from $11.09 \%$ for zone 1 to a maximum of $19.26 \%$ for zone 5 and in summer it ranges from $14.20 \%$ for zone 1 to a maximum of $19.59 \%$ for zone 5 . 
In Table 7, the minimum, maximum and mean value of the statistical indicators $N M B E$, $C V(R M S E)$ and $r^{2}$ are shown for the velocity of the air inside the channel calculated by the numerical model for the OVF using the monitoring data as benchmark. The analyzed variables are the measured and computed values in the five zones described above of the air velocity in the ventilated cavity of the OVF. Then, once the values of NMBE, CV $(R M S E)$ and $r^{2}$ are computed for the set of calculated and measured variables, the minimum, maximum and mean value of these indicators for air velocity are reported in Table 7.

Table 7. Values of the statistical indicators for air velocity.

\begin{tabular}{|c|c|c|c|c|c|c|}
\hline \multirow[b]{2}{*}{ Index } & \multicolumn{3}{|c|}{ Grill Open } & \multicolumn{3}{|c|}{ Grill Closed } \\
\hline & Minimum & Maximum & Mean & Minimum & Maximum & Mean \\
\hline & \multicolumn{6}{|c|}{ Winter. } \\
\hline$N M B E(\%)$ & 4.82 & 8.91 & 6.07 & 3.99 & 8.53 & 5.02 \\
\hline$C V(R M S E)(\%)$ & 15.67 & 22.80 & 17.07 & 14.39 & 21.09 & 16.67 \\
\hline \multirow[t]{2}{*}{$r^{2}$} & 0.7503 & 0.7989 & 0.7798 & 0.7701 & 0.8322 & 0.8083 \\
\hline & \multicolumn{6}{|c|}{ Spring. } \\
\hline$N M B E(\%)$ & -3.99 & -7.91 & -5.86 & 4.07 & 6.78 & 5.32 \\
\hline$C V(R M S E)(\%)$ & 11.71 & 22.30 & 18.82 & 11.09 & 19.26 & 15.36 \\
\hline \multirow[t]{2}{*}{$r^{2}$} & 0.7699 & 0.8090 & 0.7876 & 0.7646 & 0.8279 & 0.8033 \\
\hline & \multicolumn{6}{|c|}{ Summer. } \\
\hline$N M B E(\%)$ & 4.41 & 9.50 & 8.79 & 3.95 & 8.03 & 6.56 \\
\hline$C V(R M S E)(\%)$ & 17.08 & 23.39 & 20.21 & 14.20 & 19.59 & 17.36 \\
\hline$r^{2}$ & 0.7409 & 0.7840 & 0.7603 & 0.7429 & 0.7965 & 0.7732 \\
\hline
\end{tabular}

In accordance with Table 5 it can be stated that the outputs of simulation had a good agreement with experimental data and meet the requirements shown in this table to consider a model validated. As it can be observed in Tables 6 and 7, temperatures are well predicted, while air velocity statistics show larger errors. This difference between the precision of the simulated values of temperatures and air velocity in the framework of ventilated facades, has been pointed out in the literature [12].

\subsubsection{Model Validation: Comparison with Measurements}

In this section, some results of the temperatures calculated by the numerical model are compared to temperatures collected from experimental measurements in order to show the qualitative fit between computed and measured values.

Figures 19-21 compare the temperatures measured and calculated at the height of the sensors located in zone 4 for the exterior and interior surfaces of the outer slab and the exterior surface of the inner wall for a winter week with grid openings open. Bands of $\pm 0.5^{\circ} \mathrm{C}$ are also reported. As can be observed, the calculated temperatures lie almost all the time within the $\pm 0.5^{\circ} \mathrm{C}$ band around the measured ones. However, for some days a deviation is observed for zones in which the temperature begins to drop. This deviation is stronger for the outer surface of the inner wall as can be seen in Figure 21 where almost all the days for the lower temperatures lie outside the band, although the model exhibits the same qualitative behavior as the measured temperatures. 


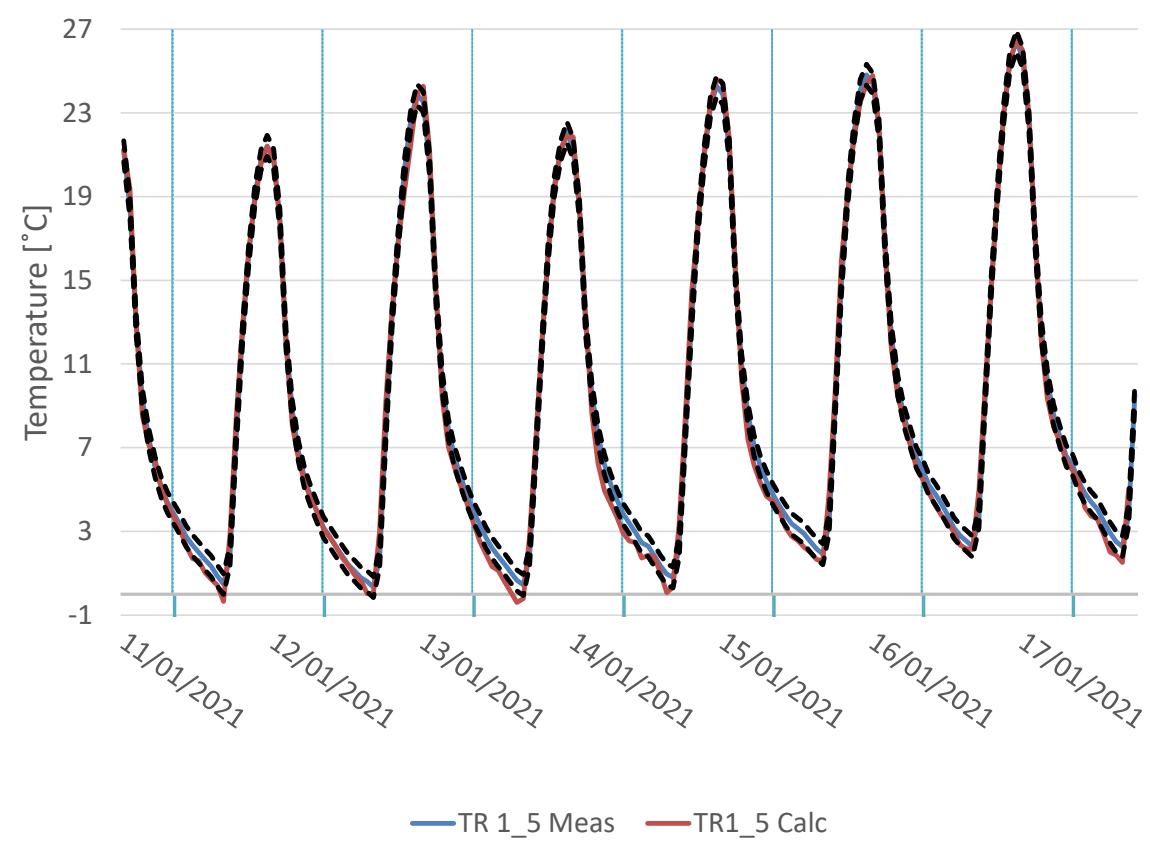

Figure 19. Cell 1. Winter. Grid open. Temperatures of the exterior face of the outer slab in Zone 4: measured (-) and calculated (-). Bands of $\pm 0.5^{\circ} \mathrm{C},(---)$, are shown.)

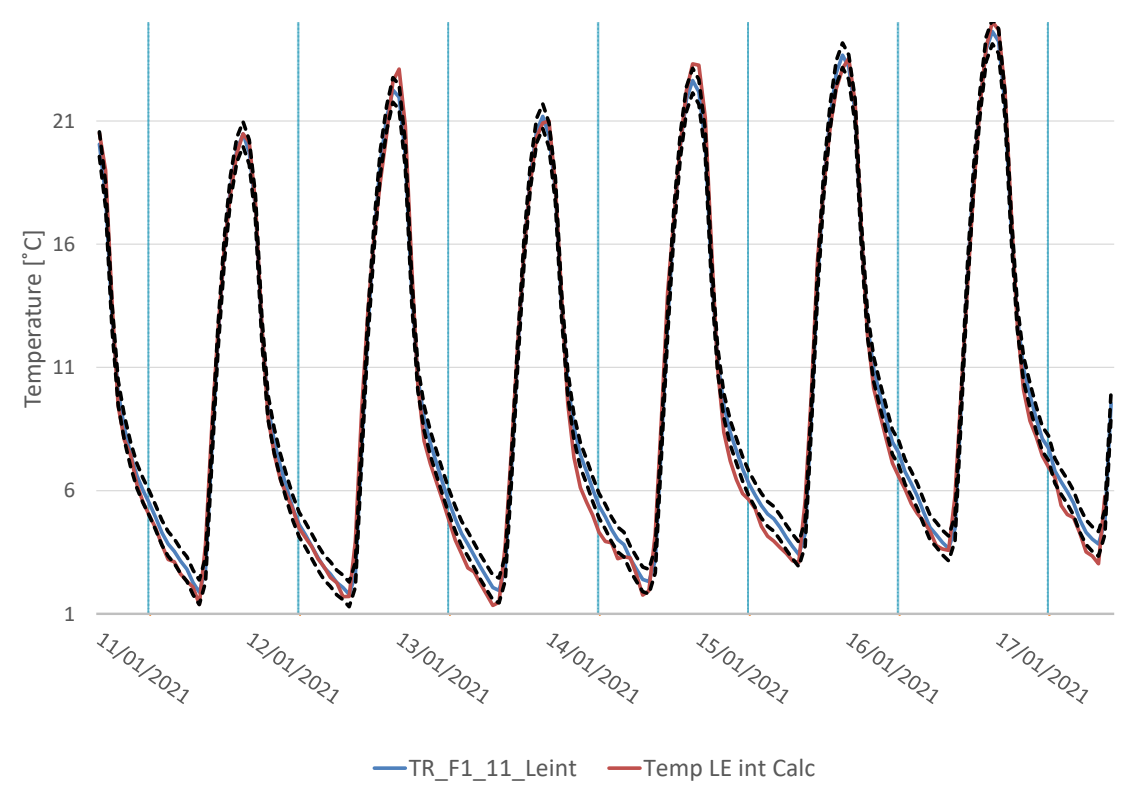

Figure 20. Cell 1. Winter. Grid open. Temperatures of the interior face of the outer slab in Zone 4: measured (-) and calculated (-). Bands of $\pm 0.5^{\circ} \mathrm{C},(--)$, are shown. 


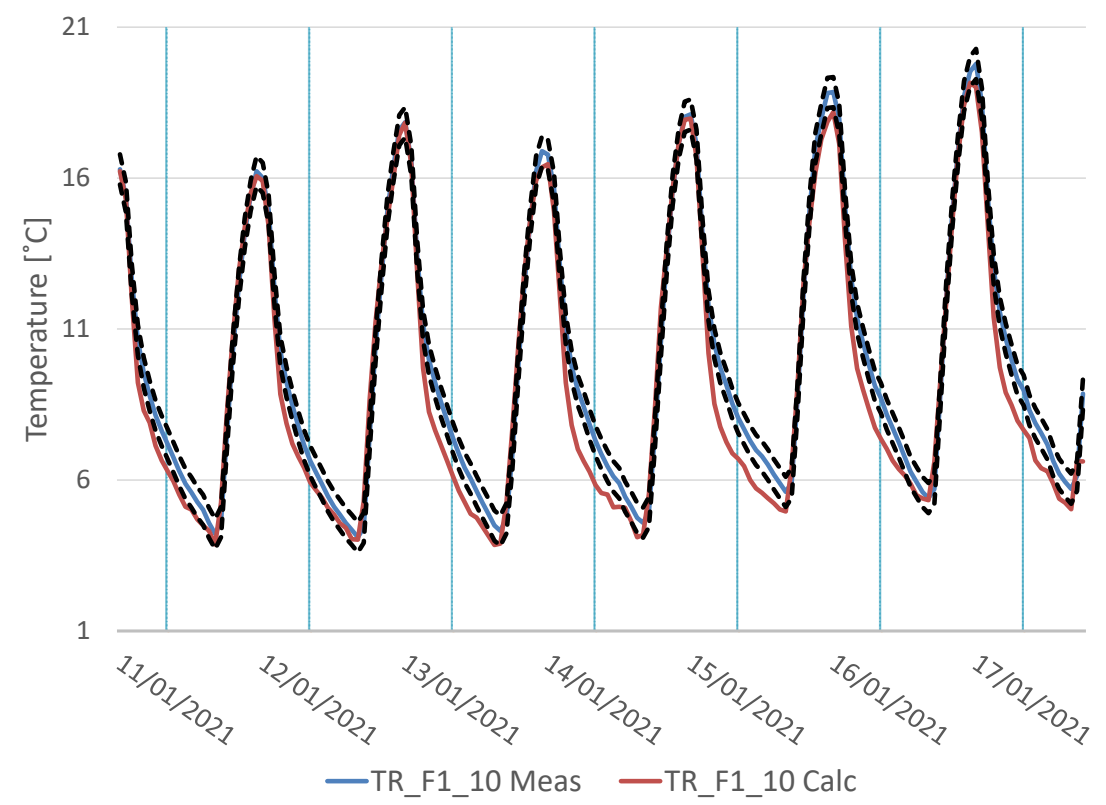

Figure 21. Cell 1. Winter. Grid open. Temperatures of the exterior face of the inner wall in Zone 4: measured (一) and calculated (-). Bands of $\pm 0.5{ }^{\circ} \mathrm{C},(---)$, are shown.

In Figures 22 and 23, the measured and calculated temperatures of the interior surface of the inner wall and the indoor air temperature for Cell 1 are compared. It can be observed the good fit between both set of values. Here the calculated temperatures lie always inside the $\pm 0.5^{\circ} \mathrm{C}$ band for the time intervals considered.

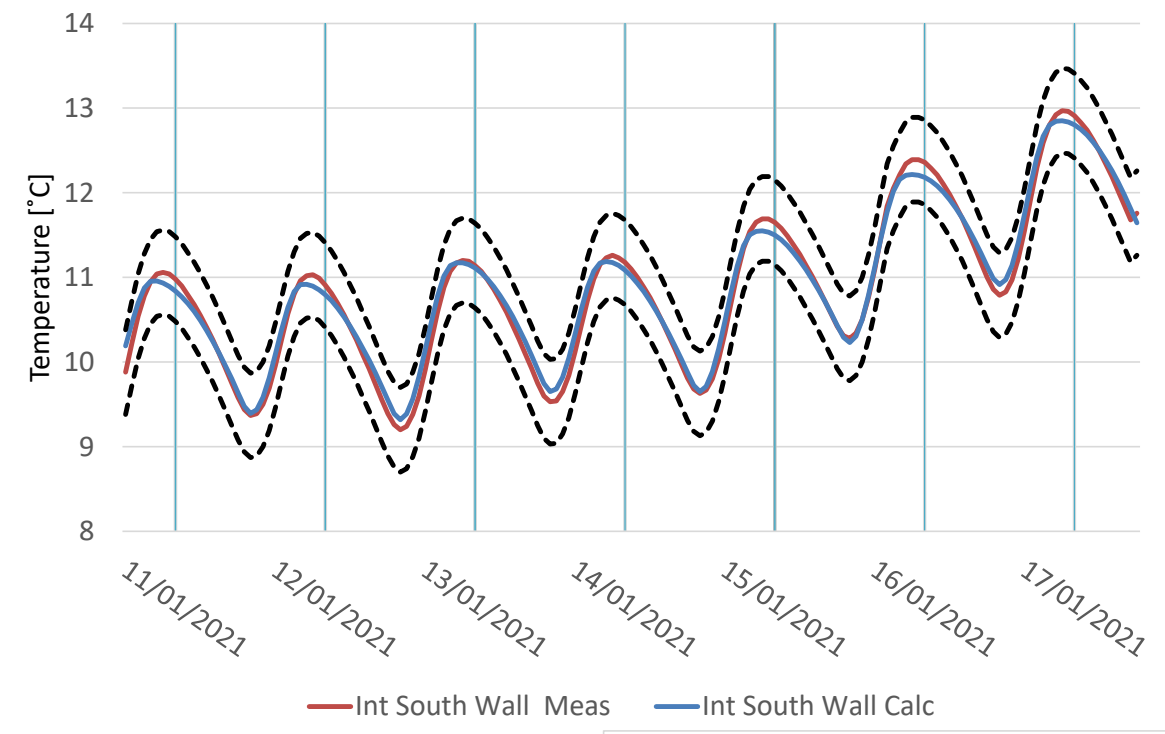

Figure 22. Cell 1. Winter. Grid open. Measured and calculated temperatures of the interior face of the inner wall in Zone 4: measured (-) and calculated (-). Bands of $\pm 0.5^{\circ} \mathrm{C},(--\mathbf{-})$, are shown.

Finally, in Figure 24, the measured and calculated temperatures at the different layers of the OVF are shown for a winter day with typical cold temperatures and high levels of solar radiation reaching the vertical southern outer surface of the OVF. It can be observed that when solar radiation increases the temperatures of the surfaces and the air in the OVF also increase. Only, on the passage of the time with radiation equal to $846\left(\mathrm{Wh} / \mathrm{m}^{2}\right)$ to the time with radiation equal to $783.9\left[\mathrm{Wh} / \mathrm{m}^{2}\right]$, it is observed, despite the decrease in solar radiation, an increase in surface and air temperatures in the OVF. This is due to an 
increase in the outside temperature between these two hours, which causes temperature to rise in the OVF despite the decrease in solar radiation. This supports the well-known finding from earlier literature that higher temperatures induce an increase in the internal temperatures of the OVF and thus a decrease in its ability to reduce heat flux into the interior. Furthermore, it can be observed that as the height increases, the temperatures of the surfaces and air increase too, according to the fact that air when raising becomes warmer due to the convective exchange with the surfaces when solar radiation reaches high values.

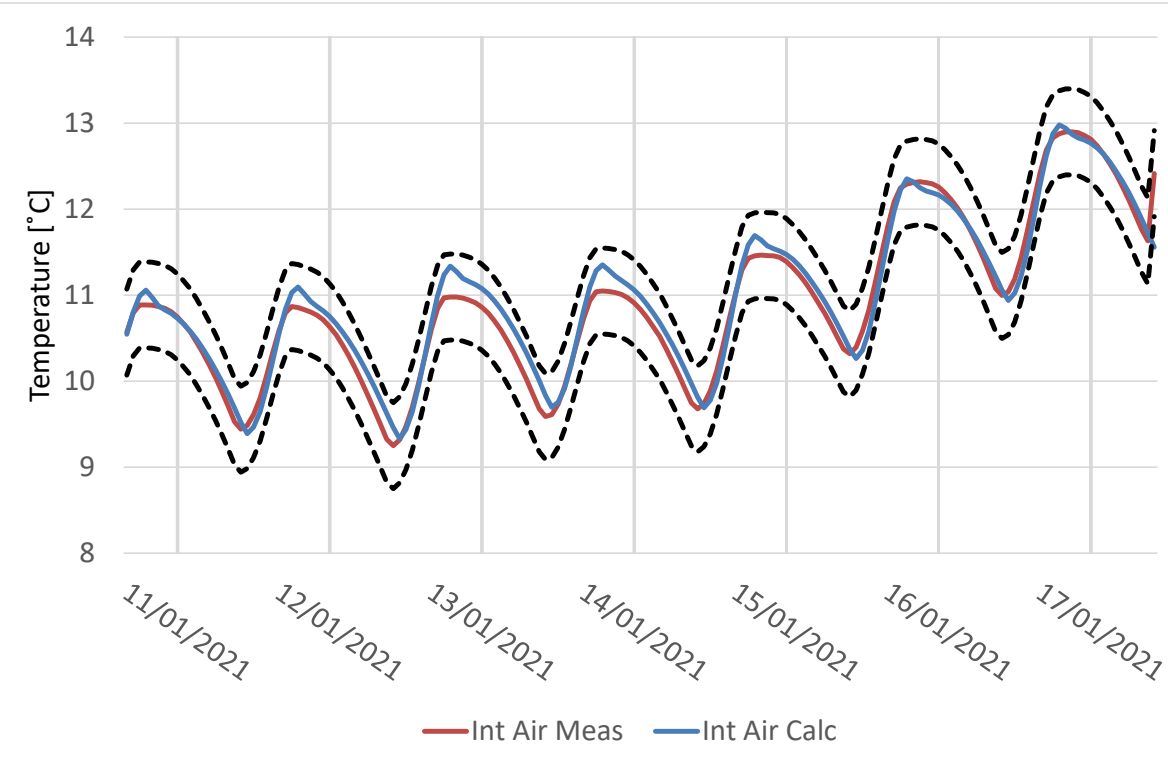

Figure 23. Cell 1. Winter. Grid open. Temperatures of the Cell 1 air indoor: measured (-) and calculated (-). Bands of $\pm 0.5^{\circ} \mathrm{C},(---)$, are shown.

It should be highlighted the role of the insulation layer in the heat dynamic of the OVF. Simulations show that the insulation layer strongly reduces inward heat flow producing an uniformization of the temperatures in the remaining layers of the wall that limits the range of variation of the interior surface temperature and therefore of the indoor air one.

Comparison of the temperature trends between calculated values Figure 12 and measured values Figure 24, as well as the comparisons shown in the previous figures in this section, allow to assert that the simulation model reproduces the qualitative behavior of the OVF observed from the experimental measurements.

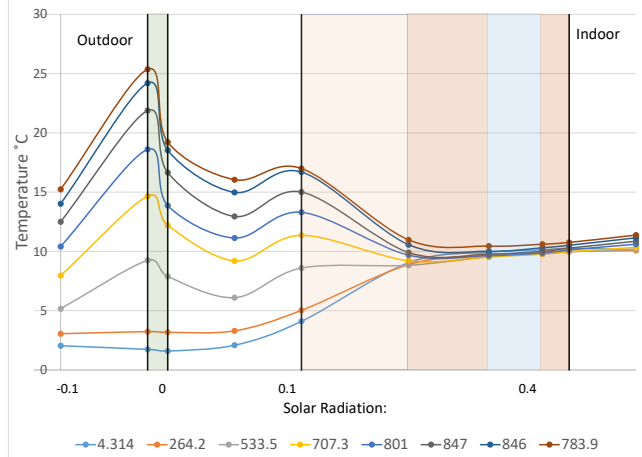

(a)

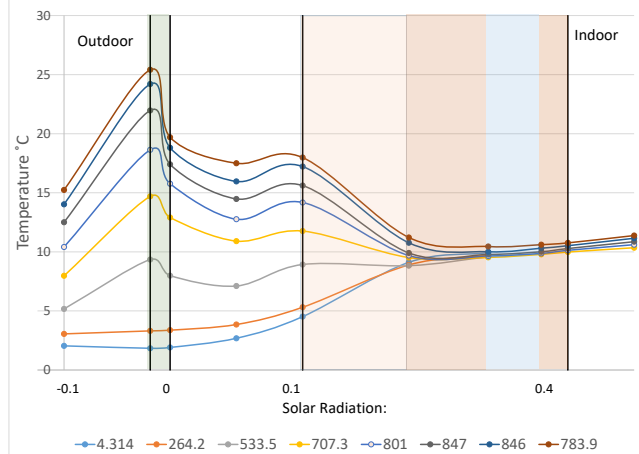

(b)

Figure 24. Trend of measured and calculated temperatures in the different layers of the southern ventilated façade for daily hours with different solar radiation and temperature values under winter conditions (14 January 2021), for: (a) Zone 2; (b) Zone 4. 


\section{Analysis of Energy Savings}

In this section, the difference between the heat flux through the OVF and through the reference UVF is analyzed for the monitored periods and for a typical climatic year in the city of Seville.

In a first stage, the energy performance of the OVFs and the reference unventilated façade ones (UVF) were analyzed and results from monitoring measures and calculated values were compared. This was done by computing the hourly heat fluxes for both façades corresponding to the different protocols of use and by using both in-field measurements and numerical simulations. Then, the heat fluxes incoming the cell indoor through the OVF, $\left(Q_{O V F}\right)$, were compared to the ones incoming the cell indoor through the unventilated façade UVF , $\left(Q_{U V F}\right)$, for the time interval corresponding to each protocol of use in order to analyze the energy savings and compare the results from monitoring to the results from simulations.

In a second stage, the simulation model for the OVF was used to estimate the energy savings of the OVFs when compared to the UVF for a typical climatic year at the city of Seville.

\subsection{Heat Fluxes and Energy Savings for Monitoring Time Intervals}

To compute $Q_{O V F}$ and $Q_{U V F}$, we follow the procedure from [9] where the heat fluxes were calculated using the following equations:

$$
\begin{aligned}
& Q_{O V F}=\sum\left(T s_{i c}(t)-T_{\text {ind }}(t)\right) / R_{O V F} \quad\left[\mathrm{~W} / \mathrm{m}^{2}\right] \\
& Q_{U V F}=\sum\left(T s_{o}(t)-T_{\text {ind }}(t)\right) / R_{U V F} \quad\left[\mathrm{~W} / \mathrm{m}^{2}\right]
\end{aligned}
$$

From measurements, the step time for $t$ can been chosen with values ranging from five minutes to one hour. Here, only hourly results are showed by the sake of brevity. It should be noted that the heat fluxes are taken as positive if the heat flux incomes to the indoor ambient and negative if it flows outward.

The thermal resistances $R_{O V F}$ and $R_{U V F}$ used in the computations of $Q_{O V F}$ and $Q_{U V F}$ are defined as [9]:

$$
\begin{aligned}
& R_{O V F}=\frac{1}{h_{\text {ind }}} \sum_{j=5}^{11}\left(\frac{e_{j}}{\lambda_{j}}\right) \quad\left[\mathrm{m}^{2} /(\mathrm{W} \cdot \mathrm{K})\right] \\
& R_{U V F}=\frac{1}{h_{i n d}} \sum_{j=1}^{6}\left(\frac{e_{j}}{\lambda_{j}}\right) \quad\left[\mathrm{m}^{2} /(\mathrm{W} \cdot \mathrm{K})\right]
\end{aligned}
$$

where $e_{j}, \lambda_{j}$ are, respectively, the thickness and thermal conductivity of the $j$-th layer of each wall and $h_{\text {ind }}$ is the mixed convective-radiative heat transfer coefficient between the inside of the internal wall and the indoor ambient. In accordance with ANSI/ASHRAE Standard 140 [53] it was taken the value $h_{\text {ind }}=8.29\left[\mathrm{~W} /\left(\mathrm{m}^{2} \cdot \mathrm{K}\right)\right]$. In Equation (13), the thermal resistance for the OVF, $R_{O V F}$, includes the layers between the air channel and the building indoor and for the UVF, $R_{U V F}$ includes the layers between the outdoor surface and the building indoor [9].

Then, for every protocol scenario, $Q_{O V F}$ and $Q_{U V F}$ are used to calculate the energy saving rate $(E S R \%)$ that following [5] and [9] is defined as:

$$
E S R=\frac{\left(Q_{U V F}-Q_{O V F}\right)}{Q_{U V F}} \times 100 \quad[\%]
$$

In Figure 25 the measured daily heat fluxes transmitted through both façades, OVF and UVF, are shown for a winter day, a spring day and a summer day. For the OVF the calculated values through the simulation model are also shown. It can be highlight that for all the cases, the heat flux incoming through the UVF façade are always higher than the one for the OVF. It is also possible to observe that values from the simulation model reproduce this pattern and are close to the measured values. Obviously this behavior of $Q_{O V F}$ and $Q_{U V F}$ means that in the central hours of the day, when solar radiation and 
ambient temperatures are higher, the UVF has a greater heat flux towards the interior than the OVF, while on the contrary,UVF can benefit during the day of a greater thermal gain, while on the contrary, at night there is a greater loss of heat, which obviously penalizes it to achieve interior comfort conditions. These results, which are also reproduced by the simulation model for the OVF, highlight the need to evaluate the global energy performance throughout the year of the OVF and the UVF, in order to conclude the possible advantages of the use of the OVF over the UFV.

In addition, it should be noted that the behaviors described for the OVF are the same for the two cases considered of grill ventilation opening closed and open. From Figure 25 is hard to draw energy behavior differences between both cases because measurement were carried out on different dates and so, the weather conditions are different. To draw conclusions about possible difference between the case of grill open and grill closed, comparative computations of the ESR and energy fluxes for the OVF can be useful, as done in next section by using the validated simulation model.

In Figure 25a it can be noted that $Q_{O V F}$ is greater than for the case with grill closed Figure 25b; however this may be due to the fact that in the period of time considered for grill open the temperatures are higher and the sun radiation slightly higher too than for the time interval where the grid is closed. The same energy behavior is observed for the UVF that is non affected by changes in openings protocols, which indicates that the observed differences in the energy behavior of the OVF can be due to the weather conditions and its relation with opening protocols needs further evidence.

More conclusive can be the comparison of Figure $25 \mathrm{c}$,d. In these figures can be observed that for lower ambient temperature and slightly lower solar radiation, in the central hours of the day the heat flux through the OVFs is higher for the closed grill that for the open grill, whilst at night the same occurs that indicates the reduction of heat transfer due to the ventilation of the OVF channel. Conversely, for the UVF the energy pattern is the opposite; on March 21, with ambient temperatures higher, the heat transfer through the UVF is higher than on April 7 when the ambient temperatures are lower. Thus, it can be concluded that the reduction in the heat transfer observed for the OVF with grid open when compared to the OVF with grid closed is due to the effect of the air flowing along the ventilated channel.

In Figure 25e,f the ambient temperatures and the solar radiation are slightly higher for the day where the grid is open with respect to the day the grid is closed. In this case, the OFV does not exhibit a significant difference between both grill patterns, but it can be noted that the flux for the UVF is higher on 5 July, with higher temperatures and solar radiation, that on 24 June. Therefore, indirectly it can be stated that this increase of heat flux observed for the UVF is muffled for the ventilation of the OVF.

In Figure 26, the daily heat flux (a) through the façades and the energy saving rates (b), both from measurements and simulations, are shown for the three time intervals considered.

For the UVF the measured daily heat flux ranges from $39.53 \mathrm{Wh} / \mathrm{m}^{2}$ in the summertime interval to $13.71 \mathrm{Wh} / \mathrm{m}^{2}$ in the springtime interval while for the OVF the measured daily heat flux ranges from $24.22 \mathrm{Wh} / \mathrm{m}^{2}$ to $4.23 \mathrm{Wh} / \mathrm{m}^{2}$ in the same time intervals as the UVF, whereas the calculated daily heat flux for the OVF ranges from $24.51 \mathrm{Wh} / \mathrm{m}^{2}$ to $4.56 \mathrm{Wh} / \mathrm{m}^{2}$ in the same time intervals. In conclusion, from Figure 26 it can be stated that the use of the OVF reduces the heat transfer through the façades for all the protocols considered.

To quantify the difference among the implemented protocols in Figure $26 \mathrm{~b}$ the ESRs for the measured and calculated values are shown. Comparing the grill ventilation open protocols to the grill ventilation closed protocols, it can be highlighted that in the time period of lower temperatures, the wintertime, the OVF with grid closed exhibits a greater ESR than for the case of grill open, according the idea that cold air flowing along the ventilated chamber colds the wall surface, whilst when the grill is closed some heat gain is obtained because the air confined in the sealed chamber acts as an insulation layer. In the other time intervals, spring and summer, the effect of opening or closing the ventilated 
chamber is just the opposite. This is because on those dates, the higher wall surface temperatures produced by the high ambient temperatures and the solar radiation are reduced by the ventilation of the OVF channel. The measured ESR varies from $63.37 \%$ for the case of spring and grid open to $46.97 \%$. The calculated values for the ESR varies from $59.42 \%$ to $42.47 \%$ for the same cases. As conclusion of the analysis of the ESR it can be stated that the OVF achieves to reduce the energy flux through the façade for all the time intervals and grid openings considered, obtaining the best results a pattern of grid closed in cold season and grid open in hot season.

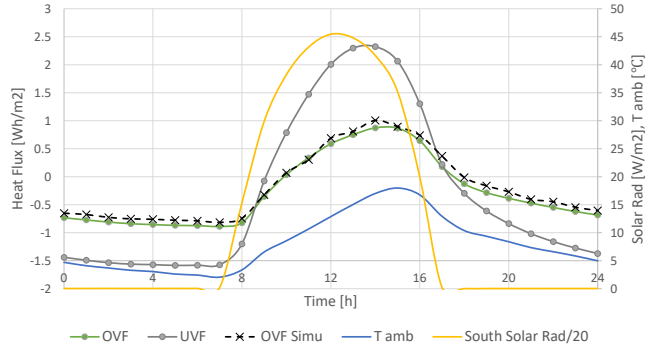

(a)

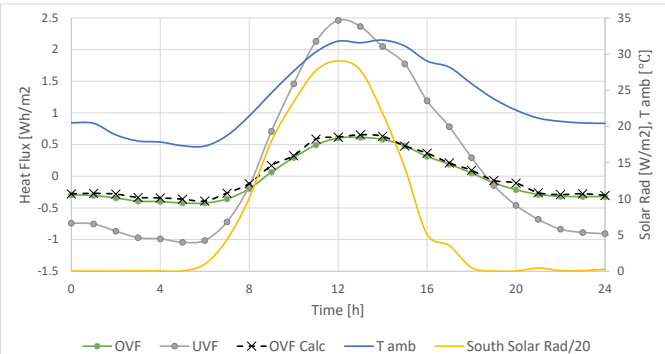

(c)

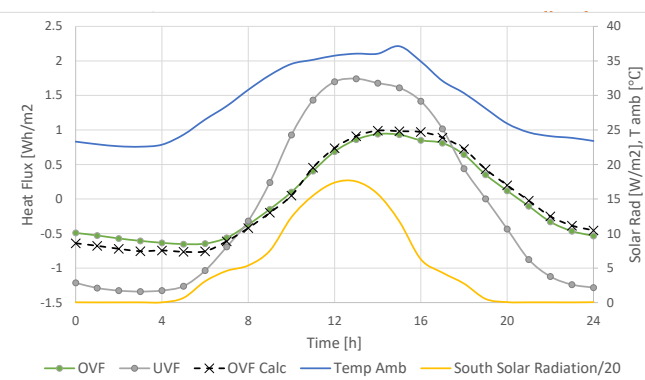

(e)

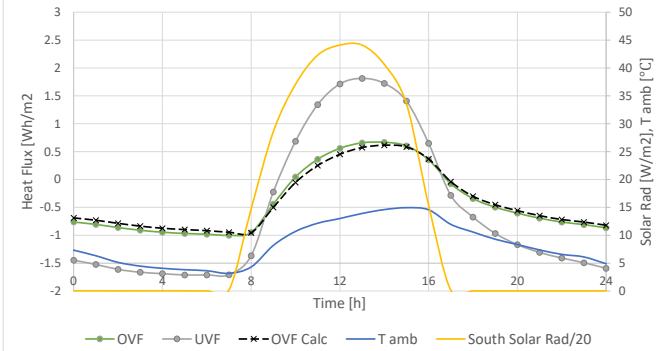

(b)

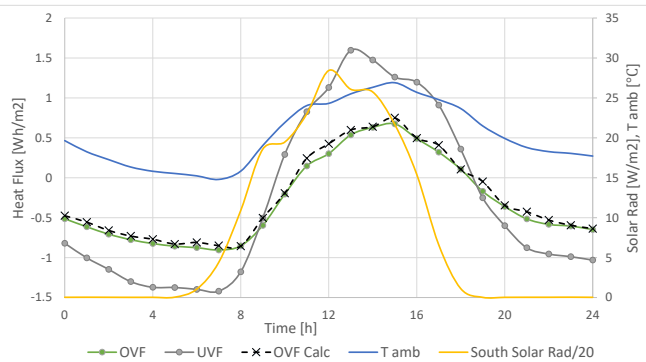

(d)

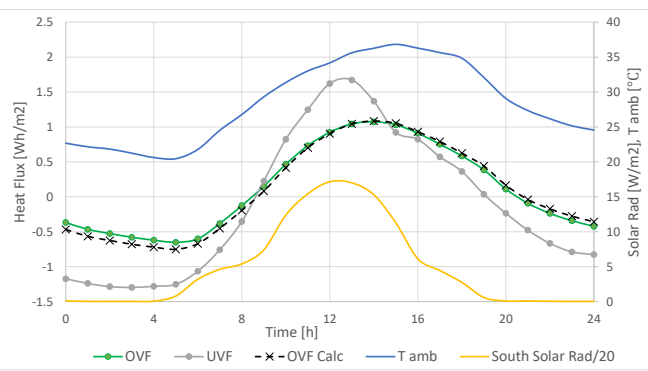

(f)

Figure 25. Hourly heat fluxes through the OVF and the UVF for: two days of winter with (a) grid open (13 January 2021), (b) grid closed (2 January 2021); two days of spring with (c) grid open (31 March 2021); (d) grid closed (7 April 2021); two days of summer with (e) grid open (5 July 2021); (f) grid closed (24 June 2021).

In Table 8, the relative errors for the calculated heat fluxes and ESRs when compared to the measured values are presented. As it can be observed, the greater errors are observed in the cases with grill open; this is probably due to the greater difficulty of approximate the thermodynamic behavior of the air when the ventilation channel is open that if closed. Finally, it should be pointed out that the relative errors range from $6.07 \%$ to $10.78 \%$ that meets the usual requirements for validation of energy simulation building models. 


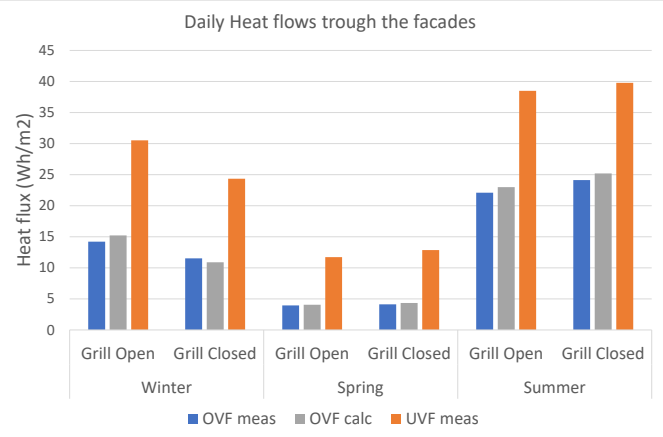

(a)

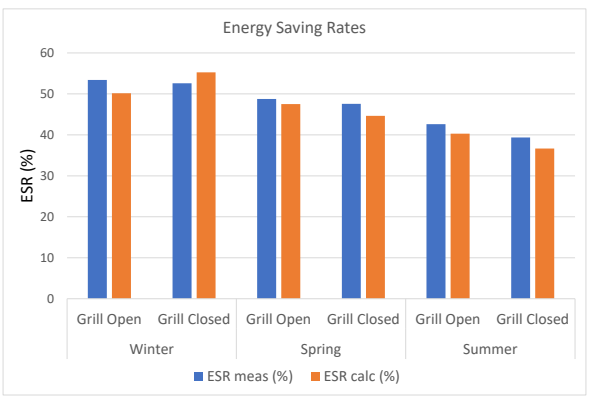

(b)

Figure 26. (a) Measured and calculated daily heat fluxes through the OVF vs. the UVF; (b) energy saving rates (\%) measured and calculated.

Table 8. Relative errors for heat fluxes and ESRs, measured vs. calculated.

\begin{tabular}{ccccccc}
\hline & \multicolumn{2}{c}{ Winter } & \multicolumn{2}{c}{ Spring } & \multicolumn{2}{c}{ Summer } \\
\cline { 2 - 7 } & $\begin{array}{c}\text { Grid } \\
\text { Open }\end{array}$ & $\begin{array}{c}\text { Grid } \\
\text { Closed }\end{array}$ & $\begin{array}{c}\text { Grid } \\
\text { Open }\end{array}$ & $\begin{array}{c}\text { Grid } \\
\text { Closed }\end{array}$ & $\begin{array}{c}\text { Grid } \\
\text { Open }\end{array}$ & $\begin{array}{c}\text { Grid } \\
\text { Closed }\end{array}$ \\
\hline Heat Flux & 7.99 & 6.62 & 10.78 & 8.49 & 8.41 & 6.91 \\
ESR & 7.10 & 6.07 & 9.59 & 7.23 & 8.22 & 7.54 \\
\hline
\end{tabular}

\subsection{Thermal Loads for a Typical Climatic Year}

In this section, in order to evaluate the energy consumption to get indoor comfort, the thermal loads were estimated for a typical climatic year for the city of Sevilla.

A continuous mode of the conditioning system was assumed. The comfort temperatures were set at a maximum of $25^{\circ} \mathrm{C}$ for the cooling season set and at minimum of $21^{\circ} \mathrm{C}$ for the heating season. For the intermediate seasons any temperature in this range was assumed to be of comfort. These values were selected according to the comfort temperature established in the Spanish regulation of thermal installations in buildings (RITE) [54].

First, the simulation model was used to compute thermal loads for the OVF and the UFV and this for a representative day for every month using climatic data from the Energy Plus climatic file (EPW file), for the city of Seville.

Computations were done on a day for every month whose climate variables values are the mean of the values for the whole month.

In Figure 27a, the thermal loads are shown for every representative month day. As can be noted, only for the months of January and February, the load for the UVF is lower than for the OVF. For the remaining months, the UVF has higher loads than the OVF. Specially in the month of August the difference is especially remarkable, according with the fact outlined in the literature of the ability of ventilated façades to reduce heat flux in hot season.

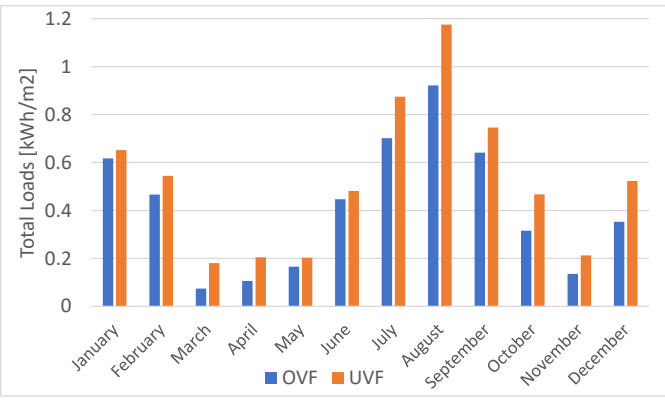

(a)

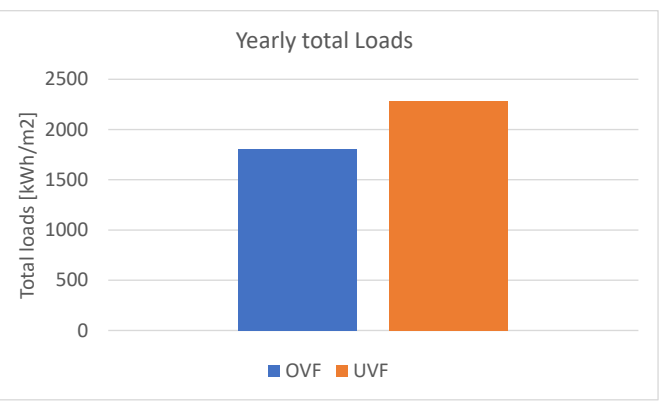

(b)

Figure 27. (a) Total loads for representative month days; (b) total loads for the whole year. 
In Figure $27 \mathrm{~b}$ by using the previous monthly computations, the total loads for the whole year are shown. It can be highlighted that for the whole year the total load through the OVF is lower than for the UVF. The ESR computed from these values is equal to $15.22 \%$ that supports the suitability of the studied ventilated façade to reduce energy consumption for get indoor comfort under operating conditions in a southern Mediterranean climate.

\section{Comparison with 2D Simulations}

This section presents the results of the comparison between the 3D model presented and a 2D model to simulate the thermodynamic and energy performance of the studied OVF. The first question that arises is how a 2D model can simulate the analyzed OVF with window opening. Obviously, it is impossible to simulate the OVF studied here in full because the 2D modeling assume a uniform transversal section of the ventilated facade, which is not the case here. Thus, it seems the most appropriate way to perform a 2D approximation of the studied OVF, to consider only a uniform section of the OVF that coincides with the OVF band defined by the zones 2, 3 and 4 shown in Figure 7 . The first drawback of this approach is that the thermodynamics of the air in zones 1 and 5 is not captured by this 2D modeling and there is no way with the usual 2D approach to simulate the lateral movement of the air in zone 1 towards the lateral zones, or the air inlet from the lateral zones into zone 5 .

To perform the 2D computations a 2D version of the 3D numerical model introduced in Section 4.1 is used. In Table 9, the values of NMBE, CV(RMSE) and $r^{2}$ are shown for the temperature of the air into the channel computed by the 2D model. As can be observed in this table, the values of the statistical indicators obtained in zone 2 for both the cases of grill open and grill closed meet the requirements of Table 5, although the values obtained for this zone are a little worse than the values obtained by the 3D simulation; this may be due to the fact that in the center of this area, where the temperature probe is placed, the air flow has an almost two-dimensional behavior in the sense that in this zone the air flow is not influenced by the airflow from zone 1 as as can be seen in Figure 17. On the contrary, the values of the statistical indicators in zone 3 and 4 are very much poor than the obtained by the 3D model and only meet the requirements of Table 5 for rare cases, mostly of then for the case of the grill closed; the apparent explanation for this is that in zone 3 the air temperatures are strongly influenced by the arrival of air from zone 1, a fact that is not captured by the 2D model where the air that reaches zone 3 only comes from the zone 2 . On the other hand, the arrival of air from zone 3 also influences air temperatures in zone 4 , where temperatures are also affected by the passage of air to zone 5 , which produces a decompression that also influences in air temperatures in the zone 4; again these facts are purely three dimensional and cannot be captured by the 2D model, this is reflected in the poor values shown in Table 9.

For the air velocities predicted by the 2D model the values of NMBE, CV(RMSE) and $r^{2}$ are shown in Table 10. Now, the values of the statistical indicator are clearly worse than for the 3D-model and rarely meet with the requirements of Table 5. Only for the case of zone 2 the values are acceptable while for the other considered zones the indicators are clearly outside of the acceptance range. The main reason for this is the purely three-dimensional character of the air flow, which is strongly determined by the obstacle that the window opening represents, and the explanation given for the influence of the air flow on the air temperature is valid also for the air velocities behavior within the channel.

Regarding the calculation of the energy flux through the OVF predicted by the 2D model, the values of this flux have been computed applying the same methodology shown in Section 7.1 used to compute the energy flux calculated using the 3D model. In Table 11, the values obtained for the energy fluxes provided by the 2D model are shown together with the values obtained for the 3D model as well as the values obtained from the monitoring in the indicated periods. In Table 12, the estimated relative errors of these computations is shown. 
Table 9. Two-dimensional (2D) simulation. Values of the statistical indicators for air temperature.

\begin{tabular}{|c|c|c|c|c|c|c|}
\hline \multirow[b]{2}{*}{ Index } & \multicolumn{3}{|c|}{ Grill Open } & \multicolumn{3}{|c|}{ Grill Closed } \\
\hline & Zone 2 & Zone 3 & Zone 4 & Zone 2 & Zone 3 & Zone 4 \\
\hline & \multicolumn{6}{|c|}{ Winter. } \\
\hline NMBE (\%) & 8.91 & -11.91 & 10.89 & 4.23 & 9.78 & 11.70 \\
\hline$C V(R M S E)(\%)$ & 11.78 & 32.89 & 35.09 & 10.71 & 27.98 & 31.18 \\
\hline \multirow[t]{2}{*}{$r^{2}$} & 0.8391 & 0.7011 & 0.6819 & 0.8617 & 0.7390 & 0.7498 \\
\hline & \multicolumn{6}{|c|}{ Spring. } \\
\hline NMBE (\%) & 7.06 & 12.47 & 11.68 & 6.12 & 11.23 & 9.67 \\
\hline$C V(R M S E)(\%)$ & 19.83 & 28.91 & 29.73 & 13.99 & 26.09 & 28.88 \\
\hline \multirow[t]{2}{*}{$r^{2}$} & 0.8447 & 0.6332 & 0.6090 & 0.8125 & 0.6689 & 0.6492 \\
\hline & \multicolumn{6}{|c|}{ Summer } \\
\hline NMBE (\%) & -6.80 & 14.09 & 12.55 & -5.76 & 13.67 & 10.56 \\
\hline$C V(R M S E)(\%)$ & 21.99 & 33.56 & 35.98 & 18.11 & 31.19 & 33.66 \\
\hline$r^{2}$ & 0.7782 & 0.6001 & 0.5903 & 0.7944 & 0.6887 & 0.6313 \\
\hline
\end{tabular}

Table 10. Two-dimensional (2D) simulation. Values of the statistical indicators for air velocity.

\begin{tabular}{|c|c|c|c|c|c|c|}
\hline \multirow[b]{2}{*}{ Index } & \multicolumn{3}{|c|}{ Grill Open } & \multicolumn{3}{|c|}{ Grill Closed } \\
\hline & Zone 2 & Zone 3 & Zone 4 & Zone 2 & Zone 3 & Zone 4 \\
\hline & \multicolumn{6}{|c|}{ Winter. } \\
\hline NMBE $(\%)$ & 8.61 & 12.45 & 11.99 & 5.69 & 13.99 & 12.02 \\
\hline$C V(R M S E)(\%)$ & 16.21 & 37.98 & 42.73 & 16.88 & 38.08 & 40.19 \\
\hline \multirow[t]{2}{*}{$r^{2}$} & 0.7489 & 0.5090 & 0.5228 & 0.7519 & 0.6101 & 0.5621 \\
\hline & \multicolumn{6}{|c|}{ Spring. } \\
\hline NMBE (\%) & -7.37 & -16.11 & -18.45 & 6.36 & 15.59 & 15.70 \\
\hline$C V(R M S E)(\%)$ & 18.64 & 32.30 & 48.12 & 11.09 & 33.76 & 35.06 \\
\hline \multirow[t]{2}{*}{$r^{2}$} & 0.7399 & 0.6143 & 0.5476 & 0.7646 & 0.5827 & 0.5190 \\
\hline & \multicolumn{6}{|c|}{ Summer. } \\
\hline NMBE (\%) & 9.37 & 14.54 & 17.43 & 7.59 & 12.92 & 14.48 \\
\hline$C V(R M S E)(\%)$ & 18.52 & 36.39 & 35.03 & 16.10 & 35.92 & 34.98 \\
\hline$r^{2}$ & 0.7331 & 0.5491 & 0.4916 & 0.7809 & 0.6212 & 0.5162 \\
\hline
\end{tabular}

Table 11. Daily heat flux through the facades: measured and computed 2D and 3D values.

\begin{tabular}{lcccccc}
\hline & \multicolumn{2}{c}{ Winter } & \multicolumn{2}{c}{ Spring } & \multicolumn{2}{c}{ Summer } \\
\hline & $\begin{array}{c}\text { Grill } \\
\text { Open }\end{array}$ & $\begin{array}{c}\text { Grill } \\
\text { Closed }\end{array}$ & $\begin{array}{c}\text { Grill } \\
\text { Open }\end{array}$ & $\begin{array}{c}\text { Grill } \\
\text { Closed }\end{array}$ & $\begin{array}{c}\text { Grill } \\
\text { Open }\end{array}$ & $\begin{array}{c}\text { Grill } \\
\text { Closed }\end{array}$ \\
\hline OVF meas & 14.22 & 11.54 & 3.95 & 4.12 & 22.10 & 24.12 \\
$\begin{array}{c}\text { OVF calc } \\
\text { 2D }\end{array}$ & 12.13 & 10.45 & 3.41 & 3.7 & 18.66 & 21.37 \\
$\begin{array}{c}\text { OVF calc } \\
\text { 3D }\end{array}$ & 15.36 & 12.30 & 4.38 & 4.46 & 23.96 & 25.94 \\
\hline
\end{tabular}

As can be seen in Table 12, in spring there is not a large difference between the errors for both models, although for the grill open there is three percentage points of difference and for the case of the grill closed this difference is close of two percentage points, always with greater error for the 2D model. However, for the winter and summer periods, the error for the 2D model are roughly the double that for the 3D for the case of grill open and a $30 \%$ greater for the case of grill close. Therefore, it can be concluded that the errors for the 2D model are always much greater than for the 3D model, with greater errors for the case of open grill and for the winter and summer periods. 
Table 12. Error for daily heat flux through the OVFs for $2 D$ and $3 D$ computations.

\begin{tabular}{ccccccc}
\hline & \multicolumn{2}{c}{ Winter } & \multicolumn{2}{c}{ Spring } & \multicolumn{2}{c}{ Summer } \\
\hline & $\begin{array}{c}\text { Grill } \\
\text { Open }\end{array}$ & $\begin{array}{c}\text { Grill } \\
\text { Closed }\end{array}$ & $\begin{array}{c}\text { Grill } \\
\text { Open }\end{array}$ & $\begin{array}{c}\text { Grill } \\
\text { Closed }\end{array}$ & $\begin{array}{c}\text { Grill } \\
\text { Open }\end{array}$ & $\begin{array}{c}\text { Grill } \\
\text { Closed }\end{array}$ \\
\hline $\begin{array}{c}\text { Error calc 2D vs. } \\
\text { meas (\%) }\end{array}$ & 14.72 & 9.43 & 13.76 & 10.19 & 15.56 & 11.4 \\
$\begin{array}{c}\text { Error calc 3D vs. } \\
\text { meas (\%) }\end{array}$ & 7.99 & 6.63 & 10.78 & 8.49 & 8.41 & 6.91 \\
\hline
\end{tabular}

\section{Conclusions}

A review of the existing literature on ventilated façades highlights that ventilated façades with window openings have received little or no attention, neither from the point of view of monitoring nor of numerical simulation.

To fill this gap, a three-dimensional numerical model for calculating the thermodynamic behavior of an opaque ventilated façade with a window was developed and an experimental and numerical analysis of the energy performance of this OVF configuration was performed. The simulation model was experimentally validated by comparing the numerical results with those provided by the monitoring of an full-scale outdoor test cell with a ventilated façade with window. Experimental measurements were performed during the first half of the year 2021 in the city of Seville, southern Spain,

The calculated values obtained using the numerical model exhibit a good fit with respect to the measured values, both from the numerical and qualitative point of view. The values of some usual indices used in model validation, support the suitability of the method developed in calculating the temperatures in the ventilated façade and the heat fluxes to the room (relative error less of $8 \%$ for the latter).

The findings from experimental analysis and from model simulation support the conclusion of a three-dimensional behavior of the air flow in the air cavity of the ventilated façade that does not allow the hypothesis of two-dimensional approach usual in the modeling of ventilated façades which justifies the need for the development of a threedimensional model. This is supported by a comparison carried out between a 2D model and the 3D model for the OVF studied; the results of this comparative analysis confirm the larger errors for the 2D model, that in some cases is close of double of the errors obtained for the 3D model.

Experimental and numerical results for the test cell with the ventilated façade were compared with the results for a test cell without ventilated façade and with the same constructive configuration, except the ventilated façade in order to draw conclusions about the energy savings and the effect of the ventilated façade to enhance internal comfort temperatures. The numerical model has been used to draw conclusions about its efficiency to reduce thermal loads by comparison with the non-ventilated façade for each month of a typical meteorological year at the city of Seville.

The main findings of the work can be summarized as follows:

- The thermodynamical behavior or the airflow in the ventilated cavity of the OVF it is genuinely three dimensional with the presence of phenomena such as vortex recirculation and lateral air displacements unfeasible to be captured by the usual 2D modeling.

- The studied OVF configuration helps to reduce the annual energy consumption to get indoor comfort compensating the winter penalty with energy savings in the cooling season. Moreover, it can help to produce healthy and comfortable indoor conditions.

- A three-dimensional numerical model has been implemented to simulate the energy behavior of an OVF with windows openings. The developed model has been used to analyze the differences between the energy performance of an OVF and a non-ventilated facade throughout a typical meteorological year of the Mediter ranean climate. 
- The 2D model of the OVF with window openings exhibits errors much larger than the 3D model, almost double in some cases.

- From the results of the calculations and measurements it can be stated that the OVF is more energy efficient than the unventilated façade. The ventilated façade analyzed is capable of providing an annual energy saving rate close to $21 \%$ conditions considered.

- It can be concluded that for the usual climatic conditions in southern Spain and Mediterranean countries, the OVF provides a significant reduction in the thermal load of the building and the annual energy consumption when compared to an unventilated façade which shows its suitability in order to be used as a efficient energy saving measure to retrofit the obsolete energy buildings built in southern Spain in the middle decades of the 20 century.

- Finally, note that the energy savings found for the case study located in the city of Seville can be directly extended to most of southern Europe and to the Mediterranean geographic area characterized by a climate similar to the one studied here.

It should be noted that the present investigation, in which, the thermodynamic behavior of an OVF with openings for windows and its impact on the energy flux toward the indoor space has been rigorously analyzed can be considered novel in the literature. Thus, although some facts can be assumed intuitively, such as the 3D thermodynamic behavior of air flows inside the OVF, their precise computation, carried out here by means of a 3D numerical method, has not been carried out before for this type of OVF configuration, and although some of the findings presented are also been found for more standard OVF configurations, as the effect of barrier from outdoor, the assessment of energy fluxes and savings for the type of OVF studied, has not been carried out previously and there is not a straightforward conclusion about the barrier effect of the OVF with window opening on the energy flux, because this effect produces a penalty on energy consumption in winter that could produce a yearly energy negative saving; therefore, the global energy flux requires careful calculations as done here. In conclusion, the items presented support the novelty of the present work in the literature on ventilated facades.

\section{Limitations of the Work and Future Research}

The main limitation of the performed studio is related with the height of the ventilated façade. This height is the equivalent of a one-story building; therefore, to broaden the scope of this research, it would be convenient to carry out a study, using the same methodology that used in the present work, for a real multi-storey building. This is part of the tasks that the research team that has carried out this work is currently developing.

On the other hand, another important limitation is the configuration of the ventilated façade studied, which, after all, is a specific case within the multiple possibilities regarding the materials used in its construction or the geometric configuration of the façade. The study of the energy behavior of a ventilated façade with window openings for different configurations is also part of the current work of the research group, one of the main objectives of this work being the optimization, from the energy point of view, of said configuration.

The effects of hygrothermal material properties and the temperature dependent thermal conductivity of the materials are also issues to be analyzed in the future work.

Likewise, the impact that the use of ventilated façades can have on reducing energy consumption in a climate change framework is another of the objectives that the working group has set for its immediate development.

Author Contributions: Conceptualization, C.-A.D.-T., Á.L.L.-R., R.S. and A.D.-D.; methodology, C.A.D.-T., Á.L.L.-R., R.S. and A.D.-D.; software, C.-A.D.-T. and A.D.-D.; formal analysis, C.-A.D.-T. and A.D.-D.; investigation, C.-A.D.-T., Á.L.L.-R., R.S. and A.D.-D.; writing-original draft preparation, C.-A.D.-T.; writing-review and editing, C.-A.D.-T., Á.L.L.-R., R.S. and A.D.-D. All authors have read and agreed to the published version of the manuscript.

Funding: This research was funded by the Ministry of Economy and Competitiveness of the Spanish Government and the European Regional Development Fund through the research and development 
project "Parametric Optimization of Double Skin Facades in the Mediterranean Climate to Improve Energy Efficiency Under Climate Change Scenarios" (ref BIA2017-86383-R).

Conflicts of Interest: The authors declare no conflict of interest.

\section{Appendix A. Equations That Govern the Air Flow}

In this appendix the equations used for the simulation of the air flow are described. Ee consider the domain described in Section 4 that will be named as $\mathrm{D}$, and consider the interval $\left[t_{0}, t_{f}\right]$ as the time interval where computations are made.

The governing equations for the air flow are the thermodynamic Navier-Stokes equations with a RNG $\kappa-\epsilon$ model for the turbulence and a Boussinesq approximation for the buoyancy. These equations can be written in $D \times\left[t_{0}, t_{f}\right]$ as:

- Conservation of momentum:

$$
\partial_{t} \vec{U}+\vec{U} \cdot \nabla \vec{U}-\nabla \cdot\left(\mu_{T} \nabla \vec{U}\right)+\nabla p=\vec{b}
$$

- Continuity:

$$
\nabla \cdot \vec{U}=0
$$

- Conservation of energy:

$$
\partial_{t} T+\vec{U} \cdot \nabla T-\nabla \cdot\left(\kappa_{T} \nabla T\right)=0
$$

- Equation of transport for the creation of turbulence kinetic energy $k$ :

$$
\partial_{t} k+\vec{U} \nabla k+\epsilon-\nabla \cdot\left(\mu_{T} \nabla k\right)=\frac{\mu_{T}}{2}\left|\nabla \vec{U}+(\nabla \vec{U})^{t}\right|^{2}
$$

- Equation for the rate of dissipation $\epsilon$ of the turbulence kinetic energy:

$$
\partial_{t} \epsilon+\vec{U} \nabla \epsilon+C_{2} \frac{\epsilon^{2}}{k}-\frac{C_{\epsilon}}{C_{\mu}} \nabla \cdot\left(\mu_{T} \nabla \epsilon\right)=\frac{C_{1} k}{2}\left|\nabla \vec{U}+(\nabla \vec{U})^{t}\right|^{2}
$$

where $\vec{U}, p$ and $T$ are, respectively, the velocity, the pressure and the temperature of the air flow; $\mu_{T}$ and $\kappa_{T}$ are, respectively, the turbulent viscosity and the turbulent thermal diffusivity of the air defined as $\mu_{T}=C_{\mu} k^{2} / \epsilon, \quad \kappa_{T}=\kappa \mu_{T} ; \vec{b}$ is the force of buoyancy due to natural convection that is given by $\vec{b}=\left[0,0,-g \beta\left(T-T_{a}\right)\right]^{t}$ being $g$ the gravitational acceleration and $\beta$ the coefficient of thermal expansion that can be approximated by $\beta=$ $1 / T_{a m b}$ under the hypothesis of ideal gases, where $T_{a m b}$ is the ambiance air temperature.

In these equations, $C_{\mu}, C_{\epsilon}, C_{1}$ and $C_{2}$ are model constants whose values are taken from [55] as $C_{\mu}=0.09, C_{\epsilon}=1.3, C_{1}=1.44$ and $C_{2}=1.92$.

\section{Appendix B. Numerical Discretization}

The numerical resolution of the equations in Appendix A was made by using a mixed $\mathbb{P} 2-\mathbb{P} 1$ finite element approximation for the velocity and pressure and a $\mathbb{P} 1$ approximation for the temperature. 
For time discretization a scheme that preserves positivity is used. This time discretization uses the method of characteristics $X^{n}(x) \approx x-\vec{U}^{n}(x) \triangle t$ being $\triangle t$ the time step. Then, the discretization in time is [56]:

$$
\begin{aligned}
& \frac{\left(T^{m+1}-T^{m} \circ X^{m}\right)}{\triangle t}-\nabla \cdot\left(\kappa_{T}^{m} \nabla T^{m+1}\right)=0 \\
& \frac{\left(\vec{U}^{m+1}-\vec{U}^{m} \circ X^{m}\right)}{\triangle t}-\nabla \cdot\left(v_{T}^{m} \nabla \vec{U}^{m+1}\right)+\nabla p^{m+1}=\vec{b}^{m+1} \\
& \nabla \cdot \vec{U}^{m+1}=0 \\
& \frac{\left(k^{m+1}-k^{m} \circ X^{m}\right)}{\triangle t}-\nabla \cdot\left(\mu_{T}^{m} \nabla k^{m+1}\right)=\frac{\mu_{T}^{m}}{2}\left|\nabla \vec{U}^{m}+\nabla\left(\vec{U}^{m}\right)^{t}\right|^{2} \\
& \frac{\left(\epsilon^{m+1}-\epsilon^{m} \circ X^{m}\right)}{\triangle t}-\nabla \cdot\left(\epsilon_{T}^{m} \nabla \epsilon^{m+1}\right)=\frac{c_{1} k^{m}}{2}\left|\nabla \vec{U}^{m}+\nabla\left(\vec{U}^{m}\right)^{t}\right|^{2} \\
& \mu_{T}^{m+1}=C_{\mu} \frac{\left(k^{m+1}\right)^{2}}{\epsilon^{m+1}}, \quad \kappa_{T}^{m+1}=\kappa \mu_{T}^{m+1}, \\
& 0 \\
& \text { where } \vec{b}^{m+1}=\left[\begin{array}{c}
-g \beta\left(T^{m+1}-T_{a m b}^{m+1}\right)
\end{array}\right] .
\end{aligned}
$$

The Equation (9) for heat transfer through the inner wall and the outer layer of the OVF have been solved by a $\mathbb{P} 1$ finite element approximation. The time discretization for these equations are made by using an implicit Euler finite difference scheme:

$$
\frac{\left(T^{m+1}-T^{m}\right)}{\triangle t}-\nabla \cdot\left(\alpha \nabla T^{m+1}\right)=0
$$

where now $\alpha$ is the diffusivity of each material. For the temperature on the solid surfaces, the boundary conditions have been chosen from the energy balance equations as it is described in Section 4.1.

In each time step the radiative balance on the surfaces is calculated and then the balance energy on the solid surfaces is used to get the border conditions for the temperature.

The FreeFem++ software [52] has been used for the computing implementation of the considered discretizations.

\section{References}

1. International Energy Agency. World Energy Outlook; IEA: Paris, France, 2000.

2. European Commission, DG Energy. A Policy Framework for Climate and Energy in the Period from 2020 to 2030. COM/2014/015 Final. 2014. Available online: https:/ / op.europa.eu/en/publication-detail/-/publication/4ef2fc24-67d0-45c2-a6d1-c677574e6 d26/language-en (accessed on 9 February 2020).

3. Balocco, C.A. A Simple Model to Study Ventilated Facades Energy Performance. Energy Build. 2002, 34, 469-475. [CrossRef]

4. Ciampi, M.; Leccese, F.; Tuoni, G. Ventilated facades energy performance in summer cooling of buildings. Sol. Energy2003, 75, 491-502. [CrossRef]

5. Patania, F.; Gagliano, A.; Nocera, F.; Ferlito, A.; Galesi, A. Thermofluid dynamic analysis of ventilated façades. Energy Build. 2010, 42, 1148-1155. [CrossRef]

6. Marinosci, C.; Semprini, G.; Morini, G.L. Experimental analysis of the summer thermal performances of a naturally ventilated rainscreen façade building. Energy Build. 2014, 72, 280-287. [CrossRef]

7. Sanjuan, C.; Suárez, M.-J.; Blanco, E.; Del Heras, M.R. Development and experimental validation of a simulation model for open joint ventilated façades. Energy Build.2011, 3456-3466. [CrossRef]

8. Giancola, E.; Sanjuan, C.; Blanco, E.; Heras, M.R. Experimental assessment and modelling of the performance of an open joint ventilated façade during actual operating conditions in Mediterranean climate. Energy Build. 2012, 54, 363-375. [CrossRef]

9. Gagliano, A.; Nocera, F.; Aneli, S. Thermodynamic analysis of ventilated façades under different wind conditions in summer period. Energy Build. 2016, 122, 131-139. [CrossRef] 
10. Stazi, F.; Tomassoni, F.; Vegliò, A.; Di Perna, C. Experimental evaluation of ventilated walls with an external clay cladding. Renew. Energy 2011, 36, 3373-3385. [CrossRef]

11. Guillén, I.; Gómez-Lozano, V.; Fran, J.M.; López-Jiménez, P.A.; Thermal behavior analysis of different multilayer façades: Numerical model versus experimental prototype. Energy Build. 2014, 79, 184-190. [CrossRef]

12. Peci López, F.; Jensen, R.L.; Heiselberg, P.; Ruiz de Adana Santiago, M. Experimental analysis and model validation of an opaque ventilated façade. Build. Environ. 2012, 56, 265-275. [CrossRef]

13. Suárez, M.J.; Sanjuan, C.; Gutiérrez, A.J.; Pistono, J.; Blanco, E. Energy evaluation of an horizontal open joint ventilated façade. Appl. Therm. Eng. 2012, 37, 302-313. [CrossRef]

14. Astorqui, J.S.C.; Porras-Amores, C. Ventilated Façade with double chamber and flow control device. Energy Build. 2017, 149, 471-482. [CrossRef]

15. Stazi, F.; Ulpiani, G.; Pergolini, M.; Perna, C.; Di Orazio, M. The role of wall layers properties on the thermal performance of ventilated facades: Experimental investigation on narrow-cavity design. Energy Build. 2020, 209, 109622. [CrossRef]

16. Gregório-Atem, C.; Aparicio-Fernández, C.; Coch, H.; Vivancos, J.L. Opaque Ventilated Façade (OVF) Thermal Performance Simulation for Office Buildings in Brazil. Sustainability 2020, 12, 7635. [CrossRef]

17. De Masi, R.F.; Festa, V.; Ruggiero, S.; Vanoli, G.P. Environmentally friendly opaque ventilated façade for wall retrofit: One year of in-field analysis in Mediterranean climate. Sol. Energy 2021, 228, 495-515. [CrossRef]

18. Stazi, F.; Ulpiani, G.; Pergolini, M.; Magni, D.; Perna, C.D. Experimental comparison between three types of opaque ventilated façades. Open Constr. Build. Technol. J. 2018, 12, 296-308. [CrossRef]

19. Li, Y.; Darkwa, J.; Kokogiannakis, G. Heat transfer analysis of an integrated double skin façade and phase change material blind system. Build. Environ. 2017, 125, 111-121. [CrossRef]

20. Lai, C.; Hokoi, S. Experimental and numerical studies on the thermal performance of ventilated BIPV curtain walls. Indoor Built Environ. 2017, 26, 1243-1256. [CrossRef]

21. Luo, Y.; Zhang, L.; Wang, X.; Xie, L.; Liu, Z.; Wu, J.; Zhang, Y.; He, X. A comparative study on thermal performance evaluation of a new double skin façade system integrated with photovoltaic blinds. Appl. Energy 2017, 199, 281-293. [CrossRef]

22. Agathokleous, R.A.; Kalogirou, S.A. Part I: Thermal analysis of naturally ventilated BIPV system: Experimental investigation and convective heat transfer coeffcients estimation. Sol. Energy 2018, 169, 673-681. [CrossRef]

23. Agathokleous, R.A.; Kalogirou, S.A. Part II: Thermal analysis of naturally ventilated BIPV system: Modeling and Simulation. Sol. Energy 2018, 169, 682-691. [CrossRef]

24. Stazi, F.; Vegli, A.; Di Perna, C. Experimental assessment of a zinc-titanium ventilated façade in a mediterranean climate. Energy Build. 2014, 69, 525-534. [CrossRef]

25. Blanco, J.M.; Buruaga, A.; Rojí, E.; Cuadrado, J.; Pelaz, B. Energy assessment and optimization of perforated metal sheet doubleskin façades through Design Builder; A case study in Spain. Energy Build. 2016, 111, 326-336. [CrossRef]

26. Colinart, T.; Bendouma, M.; Glouannec, P. Building renovation with prefabricated ventilated façade element: A case study. Energy Build. 2019, 186, 221-229. [CrossRef]

27. Recatala, M.A.; Morales, S.G.; van den Bossche, N. Experimental assessment of rainwater management of a ventilated façade. $J$. Build. Phys. 2018, 42, 38-67. [CrossRef]

28. Yang, H.; Xie, Y.; Yuan, J. Potential of self-drying siding with raised air cavities for building envelopes. Build. Environ. 2019, 152, 172-181. [CrossRef]

29. Fantucci, S.; Marinosci, C.; Serra, V.; Carbonaro, C. Thermal Performance Assessment of an Opaque Ventilated Façade in the Summer Period: Calibration of a Simulation Model through in-field Measurements. Energy Procedia 2017, 111, 619-628. [CrossRef]

30. Marinosci, C.; Strachan, P.A.; Semprini, G. ; Morini, G.L. Empirical validation and modelling of a naturally ventilated rainscreen façade building. Energy Build. 2011, 43, 853-863. [CrossRef]

31. Diallo, T.M.O.; Zhao, X.; Dugue, A.; Bonnamy, P.; Miguel, F.J.; Martinez, A.; Theodosiou, T.; Liu, J.S.; Brown, N. Numerical investigation of the energy performance of an Opaque Ventilated Façade system employing a smart modular heat recovery unit and a latent heat thermal energy system. Appl. Energy 2017, 205, 130-152. [CrossRef]

32. Peci López, F.; Ruiz de Adana Santiago, M. Sensitivity study of an opaque ventilated façade in the winter season in different climate zones in Spain. Renew. Energy 2015, 75, 524-533. [CrossRef]

33. Soutullo, S.; Sánchez, M.N.; Enríquez, R.; Jiménez, M.J.; Heras, M.R. Empirical estimation of the climatic representativeness in two different areas: Desert and Mediterranean climates. Energy Procedia 2017, 122, 829-834. [CrossRef]

34. Gagliano, A.; Aneli, S. Analysis of the energy performance of an Opaque Ventilated Façade under winter and summer weather conditions. Sol. Energy 2020, 205, 531-544. [CrossRef]

35. Fernandes Maciel, A.C.; Tereza Carvalho, M. Operational energy of opaque ventilated façades in Brazil. J. Build. Eng. 2019, 25, 100775. [CrossRef]

36. Fernandes Maciel, A.C.; Tereza Carvalho, M. Methodology used to investigate the energy savings of opaque ventilated facades in residential buildings in Brazil. MethodsX 2021, 8, 101227. [CrossRef] [PubMed]

37. Fantucci, S.; Serra, V.; Carbonaro, C. An experimental sensitivity analysis on the summer thermal performance of an Opaque Ventilated Facade. Energy Build. 2020, 225, 110354. [CrossRef]

38. Nizovtsev, M.I.; Letushko, V.N.; Borodulin, V.Y.; Sterlyagov, A.N. Experimental studies of the thermo and humidity state of a new building façade insulation system based on panels with ventilated channels. Energy Build. 2020, 206, 109607. [CrossRef] 
39. Ibanez-Puy, M.; Vidaurre-Arbizu, M.; Sacristán-Fernández, J.A.; Martín-Gómez, C. Opaque ventilated façades: Thermal and energy performance review. Renew. Sustain. Energy Rev. 2017, 79, 180-191. [CrossRef]

40. Spanish Royal Decrete 2429/1979. Approving the Basic Building on Thermal Conditions in Buildings NBE-CT-79; Boletín Oficial del Estado (BOE) 253: Madrid, Spain, 1979; pp. 24524-24550.

41. Código Técnico de la Edificación; Ministerio de Fomento del Gobierno de España: Madrid, Spain, 2009.

42. Coussirat, M. ; Guardo, A.; Jou, E.; Egusquiza, E.; Cuerva, E.; Alavedra, P. Performance and influence of numerical sub-models on the CFD simulation offree and forced convection in double-glazed ventilated façades. Energy Build. 2008, 40, 1781-1789. [CrossRef]

43. Fuentes, M.K. A Simplified Thermal Model for Flat-Plate Photovoltaic Arrays; Sandia Report: SAND85-0330-UC-63; Sandia National Labs.: Albuquerque, NM, USA, 1987.

44. Available online: http://www-eng.lbl.gov/ dw/projects/DW4229LHCdetectoranalysis/calculations/emissivity (accessed on on 18 February 2021).

45. EnergyPlus Engineering Reference; U.S. Departament of Energy: Washington, DA, USA, 2014.

46. Bejan, A. Heat Transfer; Wiley: Hoboken, NJ, USA, 1992.

47. Mirsadeghi, M.; Costola, D.; Blocken, B.; Hensen, J.L.M. Review of external covective heat transfer coefficient models in building energy simulation programs: Implementation and uncertainty. Appl. Therm. Eng. 2013, 56, 134-151. [CrossRef]

48. Liu, Y.; Harris, J. Full-scale measurements of convective coefficient on external surface of a low-rise building in sheltered conditions. Build. Environ. 2007, 42, 2718-2736. [CrossRef]

49. Hagishima, A.; Tanimoto, J. Field measurements for estimating the convective heat transfer coefficient at building surfaces. Build. Environ. 2003, 38, 873-888 [CrossRef]

50. Rohsenow,W.M.; Hartnett, J.P.; Ganic, E.N. Handbook of Heat Transfer Fundamentals, 2nd ed.; McGraw-Hill: New York, NY, USA, 1985

51. Khalifa, A.; Marshall, R. Validation of heat transfer coefficients on interior building surfaces using a real-sized indoor test cell. Int.J. Heat Mass Transfer 1990, 33, 2219-2236. [CrossRef]

52. Auliac, S.; Le Hyaric, A.; Morice, J.; Hecht, F.; Ohtsuka, K.; Pironneau, O. FreeFem++., 3rd ed.; Version 3.31-2. 2014. Available online: http:www.freefem.org/ff++/ftp/freefem++doc.pdf (accessed on 11 February 2020).

53. ANSI/ASHRAE Standard 140-2001; Standard Method Of Test For The Evaluation Of Building Energy Analysis Computer Programs American Society of Heating, Refrigerating and Air-Conditioning Engineers, Inc.: Atlanta, GA, USA, 2001.

54. Reglamento de Instalaciones Térmicas en los Edificios. Ministerio para la Transición Ecológica y el Reto Demográfico. Gobierno de España. 2019. Available online: https:/ / energia.gob.es/desarrollo/EficienciaEnergetica/RITE (accessed on 19 March 2021).

55. Launder, B.E.; Spalding, D.B. Lectures in Mathematical Models of Turbulence; Academic Press: London, UK, 1972.

56. FreeFEM Documentation (2021) Release 4.6. Frederic Hecht. 2021. Available online: http:www.freefem.org (accessed on 15 August 2021). 